Article

\title{
Blockchain-Enabled Corporate Governance and Regulation
}

\author{
Dulani Jayasuriya Daluwathumullagamage * and Alexandra Sims \\ Department of Accounting and Finance, Department of Commercial Law, University of Auckland, \\ Auckland 1021, New Zealand; a.sims@auckland.ac.nz \\ * Correspondence: d.jayasuriya@auckland.ac.nz
}

Received: 27 May 2020; Accepted: 5 June 2020; Published: 18 June 2020

\begin{abstract}
There is considerable hype about blockchain in almost every industry, including finance, with significant investments globally. We conduct a systematic review of 851 records and construct a final article sample of 183 for the sample period 2012 to 2020 to identify relevant factors for blockchain adoption in corporate governance. We conduct textual and empirical analysis to develop a decentralized autonomous governance framework and link traditional corporate governance theories to blockchain adoption. Furthermore, we explore present and future use cases and implications of blockchains in corporate governance. Using our systematic review and textual analysis, we further identify gaps and common trends between prior academic and industry literature. Moreover, for our empirical analysis, we compile a unique database of blockchain investments to forecast future investments. In addition, we explore blockchain potential in corporate governance during and post COVID-19. We find prior academic articles to mostly focus on regulation (49 studies) and Initial Coin Offerings (ICOs) (46 studies), while industry articles tend to concentrate on exchanges (10 studies) and cryptocurrencies ( 9 articles). A significant growth in literature is observed for 2017 and 2018. Finally, we provide behavioural, regulatory, ethical and managerial perspectives of blockchain adoption in corporate governance.
\end{abstract}

Keywords: blockchain; disruptive technology; corporate governance; corporate voting; tokenisation; smart contracts

\section{JEL Classification: G20; G3}

\section{Introduction}

Coined as a disruptive innovation, blockchain technology (Nakamoto 2008) has potential for creating and increasing socio-economic welfare as well as increasing the financial industry's reputation. Moreover, the use of blockchains simultaneously interacts with and challenges firms, stakeholders and financial markets. However, as identified by our study, literature solely focusing on corporate governance adoption of blockchain remains sparse. Most slightly touch on one or two applications but are primarily focused on other blockchain-related topics such as Initial Coin Offerings (ICOs) or cryptocurrencies. In addition, our study would particularly be relevant in a post-COVID-19 world, where the ability to digitally conduct business online will be paramount in the "new normal". Thus, we systematically review prior academic and industry literature for the current use of blockchains (BC) in corporate governance (CG) and regulation and link its implications to traditional theories in corporate governance. Our study identifies how academic and industry literature evolved through time and across key areas relevant to blockchain adoption in corporate governance. We further identify similarities, trends and gaps between academic and industry literature. Furthermore, we provide a behavioural, ethical and managerial perspective on blockchain adoption in corporate governance and 
regulation. In addition, we compile a unique empirical database and conduct an empirical analysis of blockchain and related start-up investments globally and forecast future blockchain investments. Finally, we develop a blockchain adoption framework in corporate governance.

We pose the following research questions: 1 . What are the current and future use cases of blockchain applications in corporate governance? 2. What are the trends, gaps and similarities between prior industry and academic literature? 3. What are the implications of adopting blockchain in corporate governance and links to theories in prior literature? 4. What are the advantages, challenges, misconceptions and limitations for blockchain adoption in corporate governance during COVID-19 and post COVID-19? 5. What are the links between investments in blockchain internationally and future forecasts? Although there is a growing literature on the development of blockchain technology, few studies explore blockchain applications, particularly with regard to corporate governance. Our study is most related to Yermack (2017), who focuses on the impact of blockchain adoption in corporate governance on various stakeholders such as managers, small shareholders, institutional investors and other parties. Yermack (2017) finds blockchain adoption in corporate governance would result in reduced cost, increase in liquidity, transparency and bookkeeping accuracy. Our study differs from these papers and prior literature in several aspects. 1. We develop a framework for blockchain adoption in corporate governance. 2. We compare academic and industry literature to identify common trends, over- and under-explored areas and evolution of literature through time for a large sample of articles (183). 3. We provide an empirical analysis of blockchains and related start-up investments globally. 4. We link theories in corporate governance to implications from blockchain adoption. Thus, this study contributes to the behavioural perspectives and structural changes not limited to firms due to technology shocks such as blockchain but including market participants, developers and regulators alike. From a social paradigm perspective, this study would appeal to academics, industry practitioners, governments, law- and policymakers, entrepreneurs and investors of blockchains.

Selected key findings from the systematic review of 851 records and a final article sample of 183 for the sample period 2012 to 2020 include the following. We identify nine primary themes from prior literature that has some relevance to blockchain adoption in corporate governance, discussed in detail in the results (Section 5.1). On one hand, academic articles mostly focus on the regulatory theme (49 studies) and ICO theme (46 studies). On the other hand, industry articles primarily focus on exchange-related themes (10 studies) and the cryptocurrency theme ( 9 articles). We observe a significant interest in both academia and industry during 2017 (48 studies) and 2018 (42 studies) in aggregate. With China's renewed investments in the Blockchain-based Service Network (BSN) and COVID-19 lockdowns driving many firms towards digital transformation, interest in blockchains is most likely to further increase in 2020.

Selected findings from the textual analysis include the following: We identify that both industry and academic literature is largely concentrated around 1. Bitcoin, 2. markets, 3. technology and 4 . fintech application themes. However, the industry and academic interests diverge in the following cases, where the industry focuses more on 1 . privacy, 2. business and 3. global themes and academia concentrates on 1. governance, 2. networks and 3. ledger themes. Giving context to these themes from the content of these literatures enables us to observe that the industry focuses more on blockchain potential on a global scale, with business applications and features of blockchain such as privacy. Meanwhile, academic literature tends to have a narrower focus, with much concentration on exploring blockchain governance and architecture.

We compile a unique empirical database from industry data sources such as PwC, ICO insights, token data, CB Insights, Statista and Hutt Capital. Primary results from our empirical analysis for quarterly data from 2013 to 2019 includes the following. A growing linear trend is observed for investments and deal count beyond 2020, with investments and deal counts in 2020 and 2021 reaching 6.173 and 6.051 USD billion and 822 and 937, respectively, despite the COVID-19 crisis. We observe a negative correlation between European blockchain investments and Asia (largely driven by China). However, there is a strong correlation between global blockchain investments and Asia. These key 
results and additional results from our systematic review, textual analysis and empirical analysis are discussed in more detail in the results and discussion (Section 5).

This study is organised as follows. Section 2 provides a literature review. Section 3 outlines the research design. Section 4 discusses blockchain technology. Section 5 includes the results and discussion from the systematic review, textual analysis and empirical analysis, including the Decentralized Autonomous Corporate Governance (DACG) Framework. Section 6 outlines blockchain adoption in corporate governance, impact and present and future use cases. Section 7 identifies the governance and ethical aspects of blockchains with regard to corporate governance applications. Section 8 explores blockchain potential in corporate governance during COVID-19 and in the post-COVID-19 environment. Section 9 discusses the limitations of our study. Finally, Section 10 concludes the study.

\section{Literature Review}

This section provides a detailed description of corporate governance and blockchain-related corporate governance literature. The findings from the systematic review of literature are provided in the results and discussion (Section 5.1). In this study, a systematic, structured literature review is undertaken to identify sources of secondary data, the historical context and best practice comparator information. While we discuss prior research on corporate governance, our objective is not to provide an exhaustive review of every aspect of blockchains in finance or corporate governance. This study is focused on the adoption of blockchain technology on corporate governance and thus would only focus on corporate governance theories that can be affected by blockchain adoption.

\subsection{Corporate Governance}

One of the first definitions widely accepted of corporate governance is offered by the Cadbury (1992), where corporate governance is defined as "the system by which companies are directed and controlled". Several adaptations of this first definition have been used later by academics in corporate governance research (du Plessis et al. 2005; Monks and Minow 1995). The agency cost theories of corporate governance state that the primary goal of good governance of firms is to protect shareholders and other stakeholders from managerial discretion. The separation between ownership, control and divergent interests of different stakeholders make it necessary to adopt governance mechanisms to align stakeholders' interests (Aguilera and Cuervo-Cazurra 2009). There are multiple corporate governance mechanisms recognized by research, both internal and external (Fama and Jensen 1983; Jensen 1993). These mechanisms attempt to reduce agency costs and guarantee an efficient decision-making process that maximizes the firm's wealth (Ahlering and Deakin 2007). Amongst the internal mechanisms, the most relevant ones seem to be the shareholders' ownership structure, the board of directors and the role of compensation of directors and managers.

In addition, transaction cost theory, first initiated in Coase's (1937) paper and later theoretically described by Williamson (1996), is an interdisciplinary alliance of law, economics and organizations. This theory defines the firm as an organization consisting of people with different views and objectives. The underlying assumption of transaction theory is that firms have become so large that they in effect substitute for the market in determining the allocation of resources. In other words, the organization and structure of a firm can determine prices and production. An alternative theory in corporate governance, which is the stewardship theory, has its roots in psychology and sociology and is defined by Davis and Thompson (1994). According to this theory, stewards are company executives and managers working towards protecting and creating wealth for the shareholders. Unlike agency theory, stewardship theory stresses not the perspective of individualism, but rather the role of top management as stewards, integrating their goals as part of the organization. Another theory in corporate governance is resource dependency theory. While stakeholder theory focuses on relationships with many groups for individual benefits, resource dependency theory concentrates on the role of board directors in providing access to resources needed by the firm. Hillman et al. (2000) contend that resource dependency theory 
focuses on the role that directors play in providing or securing essential resources to an organization through their links with the external environment.

Finally, political theory considers the approach of developing voting support from shareholders by purchasing voting power. Hence, having political influence may direct corporate governance within the organization. Public interest is much reserved as the government participates in corporate decision-making, taking into consideration cultural challenges. The objective of this study's literature review is not to discuss the entire literature on corporate governance but to identify certain theories that may be affected by blockchain adoption in the corporate governance sphere. In Section 6, our framework and several key Tables link these theories to blockchain adoption in corporate governance.

\subsection{Blockchain and Corporate Governance}

The article mostly related to our study is Yermack (2017). Yermack (2017) states that blockchain adoption in corporate governance would result in greater liquidity, lower costs, accurate record-keeping and transparent ownership. As mentioned in the introduction section, our paper significantly differs from Yermack (2017) and prior literature by developing an adoption framework, conducting a systematic review of a large sample of articles, differentiating between academic and industry literature and identifying gaps and trends, and finally linking prior traditional corporate governance theories to blockchain adoption. Catalini and Gans (2016) assert that integrations of multiple ledgers of banks via blockchain would speed up processes and reduce costs. However, Cong and He (2019) find that smart contracts can lead to increased collusive behaviour among participants. Several studies explore payment system applications for blockchains (Yamada et al. 2016) based on alternate ledger designs (Badertscher et al. 2017) and smart contracts (Atzei et al. 2017). Abadi and Brunnermeier (2018) question blockchains' ability to remain cost-effective, decentralized and accurate all at once. Houy (2014) finds that transaction fees, which are the prices paid to trade a security, are directly linked to computing power of miners. Aoyagi and Adachi (2018) develop a theoretical framework to explain cryptocurrency prices based on blockchains under asymmetric information. Kim (2017) find Bitcoin transaction costs to be $2 \%$ lower relative to standard conversion rates on average. Easley et al. (2017) test transaction fee evolution by implementing a game-theoretic model and explain users' and miners' strategic behaviour. Jayasuriya and Sims (2019) explore the effects of blockchain applications in accounting and find numerous applications including triple-entry accounting, reduced earnings management, real-time auditing.

A key differentiation to be made between blockchain-based and non-blockchain-based firms is the use of cryptocurrencies or crypto tokens. These tokens may impact operational, financing and strategic aspects of firm decision making (Rohr and Wright 2017; Chen 2018; Howell et al. 2018; Liu and Wang 2019a). Entrepreneurship-based crypto tokens enable stakeholder coordination with network externalities in a single ecosystem (Li and Mann 2018; Bakos and Halaburda 2018; Sockin and Xiong 2020). Cong et al. (2020) state that blockchain features such as immutability, transparency and wealth-sharing incentivize developers, early adopters and entrepreneurs to this particular technology. $\mathrm{Li}$ and Mann (2018) find that as the quality of the platform improves, it attracts more users and further drives up the value of the tokens, creating positive network effects.

We identify prior literature related to ICOs. However, the objective of this study is not to review ICO literature extensively but to identify aspects relevant for corporate governance and blockchains, as detailed in the results and discussion section. ICOs are a new financing mechanism for blockchain-based ventures, especially at the early stage of development (Ante et al. 2018; Kaal and Dell'Erba 2017; Zetzsche et al. 2018; An et al. 2019; Momtaz 2019a). Chod and Lyandres (2018) state that ICOs facilitate fundraising without having to relinquish control rights by the founders. Kaal and Dell'Erba (2017) compare ICOs with initial public offerings (IPOs) and state that ICOs have significantly lower issuer fees due to the non-involvement of intermediaries such as banks. Conley (2017) and Catalini and Gans (2018) state that ICOs create more demand for tokens and increased competition among token buyers and subsequently reveal consumer value. Chemla and Tinn (2017) identify similarities of ICOs to 
crowdfunding, where informed investment decisions are made through the wisdom of the crowds. Adhami et al. (2018) assert that ICO whitepapers and project-related details being widely available over the Internet will reduce information asymmetry and at the same time expose entrepreneurs to a wider range of investors. Lee and Parlour (2019) argue that ICOs provide a more liquid and secondary market for tokens listed on crypto exchanges relative to venture capital and private equity investments. However, several studies such as Collomb et al. (2018), Clements (2018) and Zetzsche et al. (2018), identify regulatory arbitrage and uncertainty around regulation as ICO disadvantages. Trimborn et al. (2018) find that majority of ICOs have a fixed token supply with a single round of financing which is required to increase token price with more demand. Liu and Wang (2019b) review prior literature on ICO token construction and valuation.

Literature that analyses ICO success include (Adhami et al. 2018; Blaseg 2018; Deng et al. 2018; Feng et al. 2018; Fisch 2018; Howell et al. 2018; Rhue 2018; Zetzsche et al. 2018; Bourveau et al. 2019 and Dean et al. 2019). Several studies focus on the quality of the management team and ICO advisors as signals of project quality and success potential (Amsden and Schweizer 2018, Lyandres et al. 2019, Bourveau et al. 2019). An et al. (2019) and Howell et al. (2018) highlight the significance of the enterpreneurs' experience, and Momtaz (2020a) and Momtaz (2019c) find CEO emotion and loyalty as being significant for ICO outcomes. Another strand of ICO literature finds significant underpricing in ICOs relative to IPOs (Adhami et al. 2018; Momtaz 2018; Bourveau et al. 2019; Ofir and Sadeh 2019). Benedetti and Kostovetsky (2018) and Momtaz (2019b) state that tokens are under-priced to attract a wider investor base and to overcome information asymmetry issues related to ICOs. Furthermore, studies such as Benedetti and Kostovetsky (2018); Momtaz (2018); Felix and Eije (2019); Drobetz et al. (2019) and Lyandres et al. (2019) focus on ICO under-pricing determinants and identify investor sentiment and first-day returns as being significant for long term ICO return prediction.

\subsection{Legal and Governance Aspects of Blockchains and Applications}

Blockchain-based firms would be a novel institution type which may require new economic analysis and governance mechanisms. Thus, several studies highlight the importance of government oversight on blockchain adoption (Davidson et al. 2016; Yeoh 2017). Other studies identify problems with ICO bans and explore optimal ICO regulation (Robinson 2017; Barsan 2017; Chohan 2017; Kaal and Dell'Erba 2017; Li and Mann 2018; Zetzsche et al. 2018). According to Kaal and Vermeulen (2017), 25 countries are considering comprehensive cryptocurrency regulation. Such regulation is key to prevent money laundering and black-market operations (Brenig et al. 2015; Abramowicz 2016; Hardy and Norgaard 2016; Humphries and Smith 2018; Foley et al. 2019). Piazza (2017) discusses blockchain adoption in corporate governance purely from a regulatory perspective. The author surmises that due to uncertainty in regulation, Bitcoin and blockchain adoption in ownership reporting and accounting is not prudent. However, Piazza (2017) does support the adoption of blockchain as a corporate voting tool. Brainard (2016) discuss various cryptocurrency regulation and courses of action. Furthermore, another strand of studies highlights the importance of regulation coordinated within society (Atzori 2015; Hughes and Middlebrook 2015; Mills et al. 2016; Robinson 2017; Nabilou and Prum 2019). Harwick (2016) discusses cryptocurrency-related, economic barriers, legal, technical, intermediation, governance factors and solutions.

Evans (2014) analyses present cryptocurrency platforms and alternatives and highlight the need for adequate governance. Tasca (2015) provides a case for country-level governance with regard to cryptocurrencies and payment systems related to financial intermediaries. Bagby et al. (2018) propose expanded jurisdiction on cryptocurrency regulatory initiatives. Luther (2016) states a lack of government support and regulation as a key barrier for cryptocurrency prevalence and success. Barsan (2017) and Pilkington (2018) discuss ICOs in general and advocate for stringent regulation to avoid hacking similar to the decentralised autonomous organisation (DAO) hack. Zetzsche et al. (2018) provide legal recommendations that would mitigate participation risks in ICOs to investors. Kim et al. (2018) explore the cryptocurrency regulatory landscape and develop a framework for cryptocurrency valuation. 
Blockchain-based regulation also involves regulation of equity crowdfunding. Zhu and Zhou (2016) explore Chinese equity crowdfunding platforms and provide blockchains as a viable solution resulting in low-cost, efficient, secure platforms requiring regulatory oversight. The next section provides a detailed description of our research design.

\section{Research Design}

This section firstly explains the research design for the systematic review and textual analysis and secondly provides the research design for the empirical analysis. The systematic survey and textual analysis enable us to identify the key diverse factors to be included in our framework. Our framework provides an overall picture of the many parties involved, theories from prior literature, market forces and the role of blockchain governance factors as it relates to blockchain adoption in corporate governance. Next, we hand-collect blockchain-related investment data globally and forecast future investments, deal counts and correlations among different geographic regions.

\subsection{Systematic Review}

As a meta-analysis method, systematic reviews are developed to explore, collect and analyse present knowledge and gaps regarding certain concepts (Briner et al. 2009). Industry and academic articles on general blockchain applications across industries and its impact have begun to proliferate in prior literature. However, each analysis in some way possesses limited scope about applications and impact on corporate governance. This proliferation further creates risks in knowledge collection and integration of findings to academics and practitioners (Briner et al. 2009). Hence, this study collates these dispersed articles in a systematic and coherent manner to identify factors relevant for blockchain adoption in corporate governance, analyse gaps, similarities and trends between the academic and industry literature and develop an adoption framework.

Given this setting, we follow (Briner and Denyer 2012) and (Moher et al. 2009) to implement a systematic literature review. The key steps are as follows. 1. Identify the motivation behind the review and formulate research questions; 2. collate the relevant articles from prior literature, conduct quality assessments and synthesise the required data; 3 . carefully analyse the final sample of articles manually and through textual analysis to identify trends, gaps and similarities between academic and industry literature and to develop the framework; and 4. finally, present the findings from our review and the developed framework for blockchain in corporate governance. We construct a final sample of 183 (28 industry and 155 academic articles) articles. These articles are finalised from a preliminary search that yielded 851 articles for the sample period from 2012 to 2020 . Further details about the article inclusion and exclusion criteria, search methods and keywords are described in detail in the next sub-sections.

\subsubsection{Definition of Research Questions}

The first stage involves motivating the study and defining the research questions. Blockchain is an ever-evolving technology and is a key part of the digital transformation process for most businesses. Hence, understanding this technology and its impact is important. However, a key part that often gets missed by most prior literature is how blockchain relates to corporate governance, its theories and implications. Furthermore, due to the proliferation of general blockchain adoption literature, it is important to conduct a systematic review to comprehend prior literature and identify insights relevant for blockchain adoption in corporate governance. To this end, the following research questions are formulated.

1: What are the present and future use cases of blockchain applications in corporate governance?

This research question identifies present and future blockchain use cases from a wide range of applications of blockchain across many industries, from general adoption articles and finance-related articles themselves.

2: What are the trends, gaps and similarities between prior industry and academic literature? 
This question is formulated to obtain an overview of over- or under-explored areas and differences of interest between the industry and academic literature with regard to blockchain and corporate governance. The findings related to this research question would aid future researchers and industry practitioners to identify gaps where more research and applications are required and would promote collaborations between industry and academia.

3. What are the implications of adopting blockchain in corporate governance and linking to theories in prior literature?

Clearly identifying the impact of blockchain adoption for corporate governance is key for successful deployment and maintenance of blockchain within the finance industry. By linking existing traditional corporate governance theories to blockchain adoption, this research question aids in better understanding impacts and unintended consequences.

4: What are the advantages, challenges, misconceptions and limitations for blockchain adoption in corporate governance during and post COVID-19?

Due to lockdowns and social distancing, most businesses have been pushed for digital transformation at a faster pace, including those in the financial sector. Blockchain being one of the key fintech technologies, this research question aims to understand the advantages, limitations and barriers of adoption of blockchain in corporate governance during and post COVID-19.

5. What are the links between investments in blockchain internationally and future forecasts?

This empirical research question collates empirical data on blockchain investments from several data sources and forecasts future investments to identify future investment trends.

\subsubsection{Collating Articles}

This section details the steps followed for article selection. We carried out a systematic literature search in Science Direct, Business Source Premier, Scopus and Google Scholar. The article collation process involved the following steps: 1. database identification (Science Direct, Scopus, Business Source Premier and Google scholar); 2. finalising keywords and search criteria (for the preliminary search); 3. identifying the initial set of articles and analysing manually and through textual analysis; 4 . constructing the final sample of articles; and 5. classifying the identified relevant articles into major themes; Science Direct, Scopus and Google Scholar were selected as suggested by finance specialist librarians at the university as being the primary databases ${ }^{1}$ with an exhaustive list of industry and academic articles relevant to blockchain technology in finance.

The article search included several permutations of the following keywords: "finance+blockchain", "decentralised system+finance", "decentralised network+finance", "decentralised ledger+finance", "cryptocurrencies+corporate governance", "digital currencies+corporate governance", "bitcoin+corporate governance", "Ethereum+finance", "ICO+finance," "financial services+blockchain", "security+blockchain", "ethics+blockchain", "blockchain+corporate governance", "financial intermediaries+blockchain", "COVID-19+blockchain", and "regulation+blockchain" in the title, abstracts, text, and keywords fields of the search engine. Moreover, the reference list from selected articles was further analysed to identify more articles not previously captured by the search criteria (snowball effect). This preliminary search yielded 851 records in total from all the databases. These articles include peer-reviewed research articles, conference proceedings papers, consulting and professional body reports, white papers, book chapters, short notes and short surveys. Subsequently, we segregated academic and articles and constructed a final sample of 183 blockchain-related articles (28 industry and 155 academic articles), which was used in the analysis, possessing factors relevant to or that can be re-purposed for corporate governance.

1 Several search refinement features of Scopus and Science Direct are used following specific articles that might be in a grey area with regard to interest. However, for good measure we conducted a regular Google search as well and reviewed search results so as not to miss important industry reports. 


\subsubsection{Final Article Sample Selection}

The pre-defined inclusion/exclusion criteria in Table 1 aid in constructing the final sample of articles. Several exclusion criteria are implemented prior to including the articles in the bibliographic manager. These included perusing for language, document type (notes, editorials) and further removing articles that contain no information relevant to blockchain adoption in corporate governance. In the initial stage, all articles' keywords, abstracts and introductions were assessed. Subsequently, any article that met one of the exclusion criteria was excluded. Several articles were further excluded following a full text review and being purely related to technical aspects of blockchain technology. Additional articles related to finance, corporate governance and survey methodologies are included in the reference list of the study but not included in the review analysis as they are not related to blockchain technology.

Table 1. Inclusion and exclusion criteria.

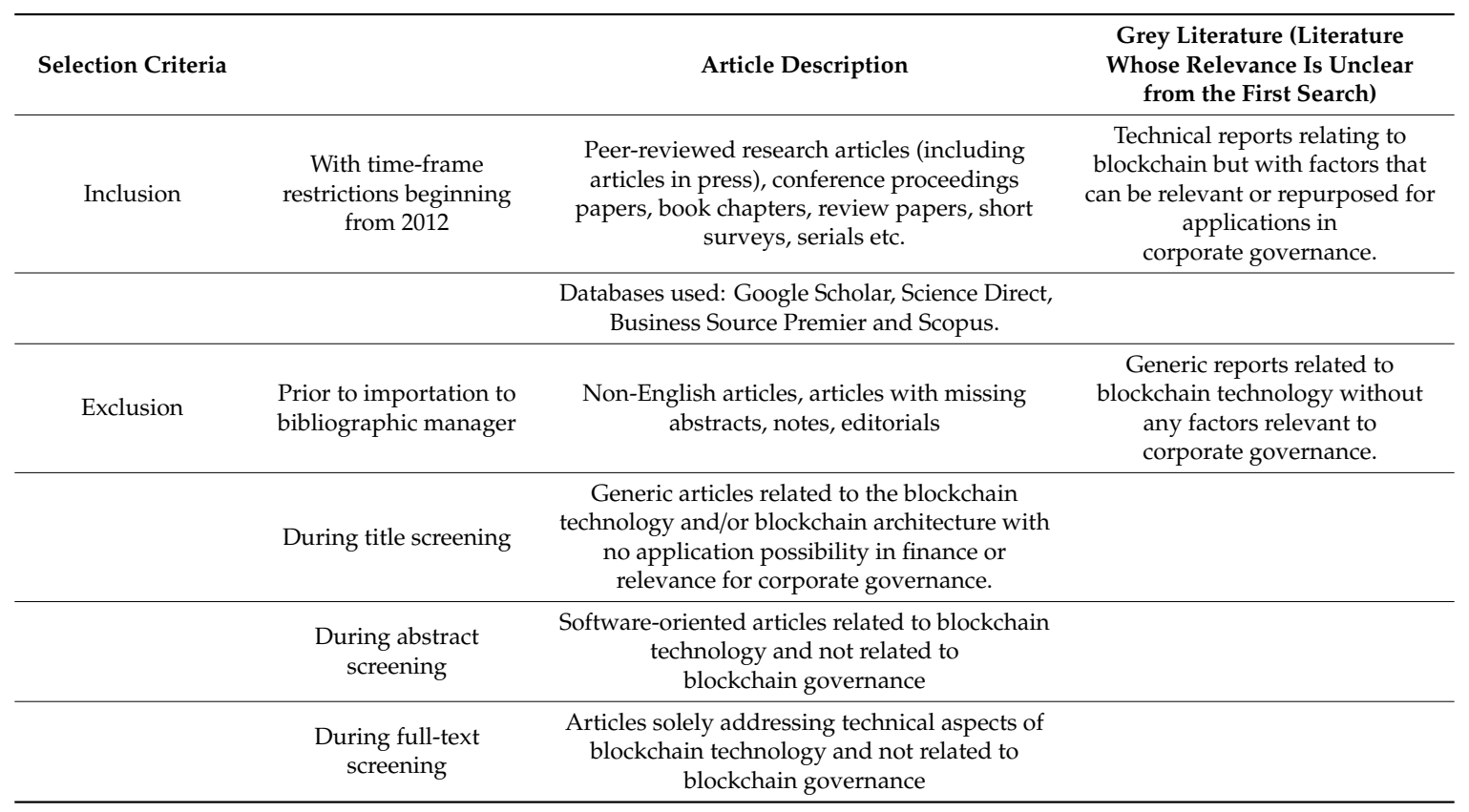

\subsubsection{Textual Analysis and Thematic Coding}

All articles in the final sample are submitted to machine-learning-based textual analysis software named 'Leximancer'. Through Leximancer, key themes and sub-themes are identified for the framework development and further differentiation between industry and academic literature. Additional factors to the framework are included by carefully reading the articles in the final sample for robustness of the results from Leximancer and to provide context to the key themes identified by the software. Thematic content analysis through Leximancer is conducted via resource maps, and detailed results are explained in Section 5.2.

\section{Resource Maps}

A resource map provides a broad view of a large amount of literature in one single graph. The size of each concept point indicates its connectedness. As the algorithm goes through the list, it will attempt to draw words as close as possible to the centre of the visualization. These key themes and sub-themes identified via the resource maps and the manual systematic review of prior literature form the foundation for our DCAG. 


\subsection{Empirical Data Collection and Methodology}

Due to blockchain's relative novelty, its exponential development and secrecy by adoptive firms due to future profitability prospects, empirical data with regard to blockchain applications are difficult to obtain (Dapp 2014). Given this setting, for the empirical analysis, firstly, we hand-collected and compiled a unique quarterly database from 2012 to 2020 of blockchain and related start-up investments globally through historical reports from PwC, Token Data, CB Insights, ICO Insights, Statista and Hutt Capital. The future values are forecasted using a basic average linear extrapolation on past values due to the lack of a number of observations and additional data.

\section{Blockchain Technology}

Blockchain is just one form of the broader area of distributed ledger technology (Brainard 2016). Given the widespread use of the term "blockchain", we use that term instead of distributed ledger technology (DLT). There are two main types of blockchains: public and permissioned. On a public blockchain, such as Bitcoin, no permission is required to use or view the blockchain. The two highest-profile public blockchains are Bitcoin and Ethereum (Atzei et al. 2017). Bitcoin was the first blockchain (Nakamoto 2008). Most public blockchains are open-source, and no central authority or person runs a public blockchain. Rather, a network of peers agrees on the state of the blockchain. Newer platforms such as IOTA, Hashgraph, Holochain and Dfinity do not use a chain of blocks (Wright and De Filippi 2015). Verification on the Bitcoin blockchain is made via peers (miners). Bitcoin's blockchain is a ledger that records the number of bitcoins an entity owns in a particular wallet (Abadi and Brunnermeier 2018). It also contains a full transaction history of all transactions sent and received by that particular wallet. People or entities are not defined by their names, as they would be for a bank account; rather, public keys are used (Chen 2018). Public keys are a long string of numbers and letters. The Bitcoin blockchain records the bitcoins each public key owns. A public key, in turn, is controlled by the individual who has the private key (another long string of numbers and letters). Whoever has access to the private key is able to transfer bitcoins, highlighting the importance of the security of the private key (Atzei et al. 2017). Crucially, unlike with a password for a bank account, there is no ability to recover a lost or forgotten private key.

Miners are incentivized to perform the validation and block creation work by a block reward: a reward of bitcoin for successfully adding a block to the blockchain, plus the transaction fees from the transactions the miner includes in the block (Babich and Hilary 2019). The block reward further serves to distribute newly created bitcoin. Bitcoin is currently capped at 21 million bitcoins and it is expected that in approximately 2140, the last bitcoin will be created. Once the last bitcoin is created, miners will receive only transaction fees that are attached to transactions (Beck et al. 2018). Transactions cannot be altered after the fact, although it is possible in exceptional circumstances to make retrospective changes (DuPont 2017). Bitcoin and its proof-of-work consensus system have been criticized for their electricity use, although Vranken (2017) has questioned the estimates. Several blockchains, mindful of electricity usage, use proof-of-stake or delegated proof-of-stake, which do not expend large amounts of electricity, as nodes are chosen at random to validate transactions (Vranken 2017). For example, proof of importance consensus is used in the NEM blockchain. Permissioned blockchains, which are considered next, do not normally use proof-of-work and thus have minimal electricity requirements (Vranken 2017). Permissioned blockchains, as the name suggest, can limit who has permission to validate transactions, view the blockchain and create transactions. Permissioned blockchains are generally run by consortiums. Fewer participants translate to a permissioned blockchain that is not as decentralized as a public blockchain (Beck et al. 2017). Several public blockchains, such as Ethereum and NEM, offer permissioned versions. 


\subsection{Smart Contracts}

Smart contracts are a set of instructions residing on a blockchain, written in computer code, and are a key aspect of harnessing blockchains' capabilities. Szabo (1994) states that a smart contract can execute the terms of a contract and is a computerized protocol. They can be used, for example, to guarantee payment by counterparties involved in a contract. Ethereum is the first blockchain to successfully employ smart contracts. The self-enforcing nature of smart contracts results in transaction costs of monitoring and enforcing adherence to rules and laws being removed (Cong and He 2019). Sisli-Ciamarra (2012) states that firm board composition may also be affected by smart contracts. Generally, firms have bankers as directors to signal financial markets' creditworthiness, and smart contract signalling may deter this need. Mik (2017) argues that smart contracts can be implemented to solve numerous legal and enforcement issues. In our opinion, applications of smart contracts in corporate finance and governance could include option exercises and other contingent claims requiring instant collateral transfer in case of default. They can also include performance-based employee compensation packages. Moreover, smart contracts alleviate agency costs in many of these scenarios in corporate governance (Yermack 2017). Finally, a firm's willingness to implement smart contracts can signal future ethical behaviour.

\subsection{Decentralized Autonomous Organizations (DAO)}

Organizations/firms are deemed to be a natural mechanism for conducting businesses, and this form of organization dates back to the mid-19th century (DuPont 2017). However, blockchains have the potential to transform the future organization to a digitized decentralized network of stakeholders (DuPont 2017 and Sims 2019). In our opinion, blockchains can facilitate a form of novel organization without senior management or an organizational hierarchy. Blockchains are an opportunity for new organization types to develop based on a distributed decentralized structure (Scott et al. 2017). Shermin (2017) argue that blockchains can overcome traditional principal-agent dilemmas through decentralized governance and highlight the importance of smart contracts to implement a trust regulatory system. A DAO is an amalgamation of blockchains, smart contracts and stakeholders all working together interactively. The basic rules of governance are programmed into the blockchain at setup (DuPont 2017). All stakeholders involved with the DAO will possess tokens that represent a share in the DAO's performance (similar to a share of an organisation/firm). Therefore, the fundamental profit maximisation goal of the firm can be restated as the value maximisation of the tokens for a DAO (DuPont 2017). Essentially, in our opinion, a DAO is an organisation controlled by token holders that operate on a blockchain through smart contracts. Thus, DAOs will have to be governed by laws and regulations similar to all regular firms in order to interact and conduct business in the real world. Therefore, these token holders will replace board members AND top management, where decisions would be made by token holders. Moreover, the type of token possessed by each token holder may determine the type of contract for each project within the DAO, similarly to an employee in a regular organization/firm.

\section{Results and Discussion}

This section firstly discusses the systematic review results, then the results from the textual analysis and DACG framework and finally moves on to the empirical results. Moreover, this section answers Research Question 2: What are the trends, gaps and similarities between prior industry and academic literature? The key findings from the systematic review section involve the identification of nine key themes with regard to prior literature, the time trends and cross-sectional distributions of these literature, common trends and over- and underexplored themes between industry and academic literature. 


\subsection{Systematic Literature Review Results}

The study analyses 183 articles, out of which 28 are from the industry for the sample period from 2012 to 2020. By reading through prior literature, we are able to broadly classify them into the following key themes: 1 . exchanges and CG, 2. corporate voting and CG, 3. practice and education of $\mathrm{BC}, 4$. BC and CG, 5. regulation, 6 . BC technology related to $C G, 7$. ICOs and crowdfunding, 8 . cryptocurrencies and 9. other. The "Other" theme includes articles with a prime focus in another area than the themes identified with regard to blockchain but still having some relevant factors to draw upon for blockchain adoption in corporate governance.

\section{Academic and Industry Article Comparison}

Table 2 identifies the number of articles that focus on the key themes utilized to develop the decentralized autonomous corporate governance framework (DACGF) in this study. According to Table 2, the industry focus is primarily on the two themes of stakeholders (23 studies) and blockchain impact and value creation (20) from our DACG framework. Academic studies primarily focus on market mechanisms (60 studies) and blockchain governance (57 studies). Corporate governance emerges as an underexplored area by both academic ( 7 studies) and industry (1 study) literature, highlighting the importance of our study and the DACG framework. Table A1 is provided as a separate Internet Appendix A for brevity and identifies the themes from the systematic review on blockchain adoption in corporate governance among academic studies and industry articles.

Table 2. Focus counts for framework development from prior literature.

\begin{tabular}{cccc}
\hline Framework & \multicolumn{2}{c}{ Focus on Any Factor within Theme } \\
\hline Key Themes & Total & Industry Reports & Academic Studies \\
\hline $\begin{array}{c}\text { Corporate governance theories relevant } \\
\text { to blockchain adoption }\end{array}$ & 8 & 1 & 7 \\
Blockchain impact and value creation & 54 & 20 & 34 \\
Stakeholders & 53 & 23 & 30 \\
Market mechanisms & 74 & 14 & 60 \\
Blockchain governance & 60 & 3 & 57 \\
\hline
\end{tabular}

Source: CB insights, PwC, ICO Insights and Token Data.

Figure 1 depicts the industry and academic article count across time, and Figure 2 provides the article count by key themes for industry and academic literature and the aggregate of both. In Figure 2, several articles from both industry and academic may overlap across several themes. Figure 2 further enables us to identify the trends, gaps and similarities between academic literature and industry reports.

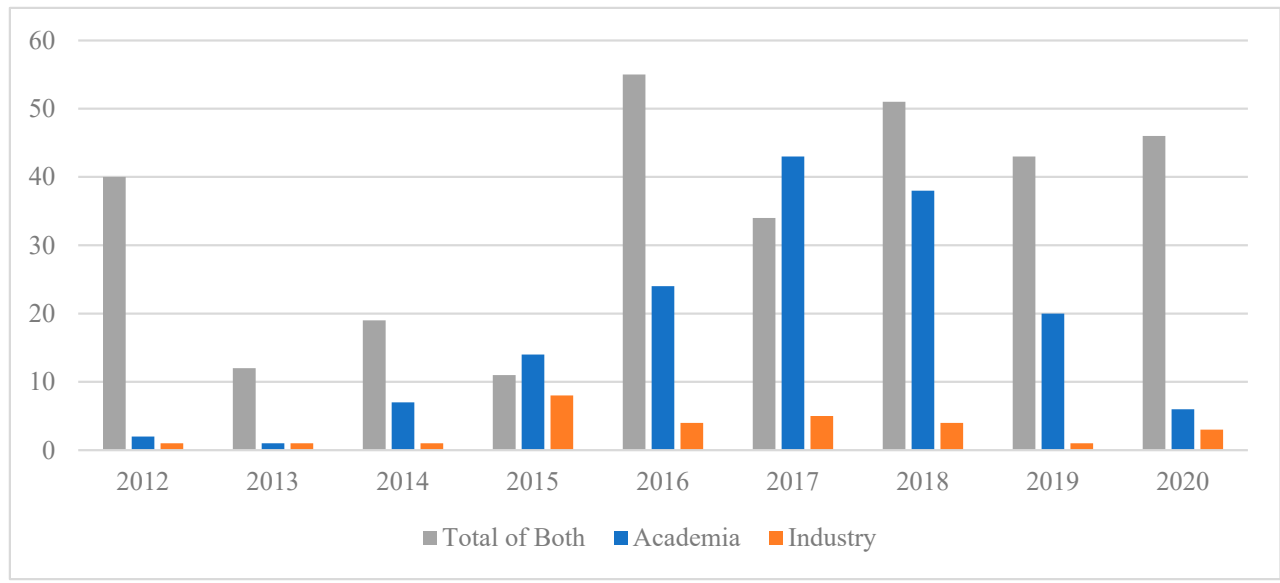

Figure 1. Year-wise article count. 


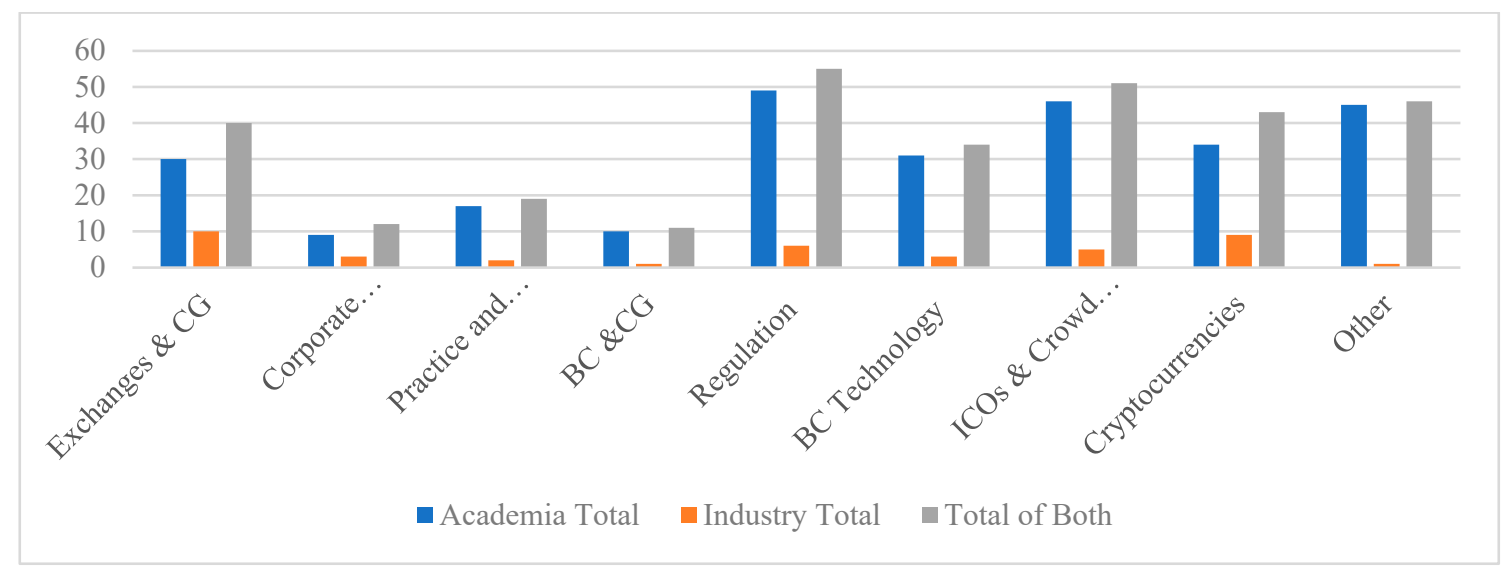

Figure 2. Topic-wise article count for academic and industry articles and total aggregate.

According to Figure 1, articles skyrocketed during 2017 and 2018 for academia, with 43 and 38 and for industry, with 5 and 4 articles, respectively. However, the year with the greatest number of articles from the industry with some relevance for corporate governance was 2015 (8 studies). This count suggests that academia seems to lag behind industry by two years in terms of blockchain articles with factors relevant for corporate governance. Due to some stringent regulatory measures and bans in 2018 in China, there is a significant decline post-2018 (Allan and Hagiwara 2018), with only 20 academic studies in 2019. This trend is likely to reverse with interest picking up due to COVID-19 and renewed interest from China. Figure 2 displays the theme-specific distribution of our sample of 183 articles. These themes are identified from our systematic review as opposed to the earlier themes mentioned that are directly from our DACG framework. According to Figure 2, academic articles mostly focus on regulation (49 studies) and ICOs (46 studies). Industry articles primarily focus on exchanges (10 studies) and cryptocurrencies ( 9 articles). This result is understandable, as most industry applications tend to focus on digital or cryptocurrencies and their many applications in financial services. These numbers highlight the interdisciplinary potential of blockchains across industries.

\subsection{Textual Analysis}

The first step in manually identifying differences, gaps and trends between academic and industry literature involves carefully reviewing the text body. However, as an additional step, these three resource maps further help to differentiate between academic and industry literature. Moreover, to develop the DACG framework, we use textual analysis to obtain a broad perspective of prior literature and industry reports. Through this, we identify the key themes and which studies are clustered around them as explained in the first part of Section 5.1.

\section{The Map}

The resource maps below provide information about the main concepts across the literature analysed and finally the similarities in the contexts in which they occur. This analysis helps us to develop our DACG framework and to identify key themes. Figure 3 shows words such that the terms that occur the most frequently are positioned centrally and are of the largest size for academic and industry literature, thus, providing an overall birds-eye view of the entire sample of 183 articles. According to the large-sized and nearby linked words, we can observe that Figure 3 identifies 1. blockchain, 2. technology, 3. markets, 4. financial, 5. shareholders, 6. transactions, 7. information and 8. transparency as key themes emerging from prior literature. By coding those themes and giving them context, we can identify that they relate to focus on blockchain technology itself: blockchains in finance and financial markets, blockchains in exchanges with links to shareholders, blockchains for payment systems with links to transactions, and finally blockchain features such as transparency 
and information on a blockchain. Further examples and explanations of blockchain applications are explained in Section 6.

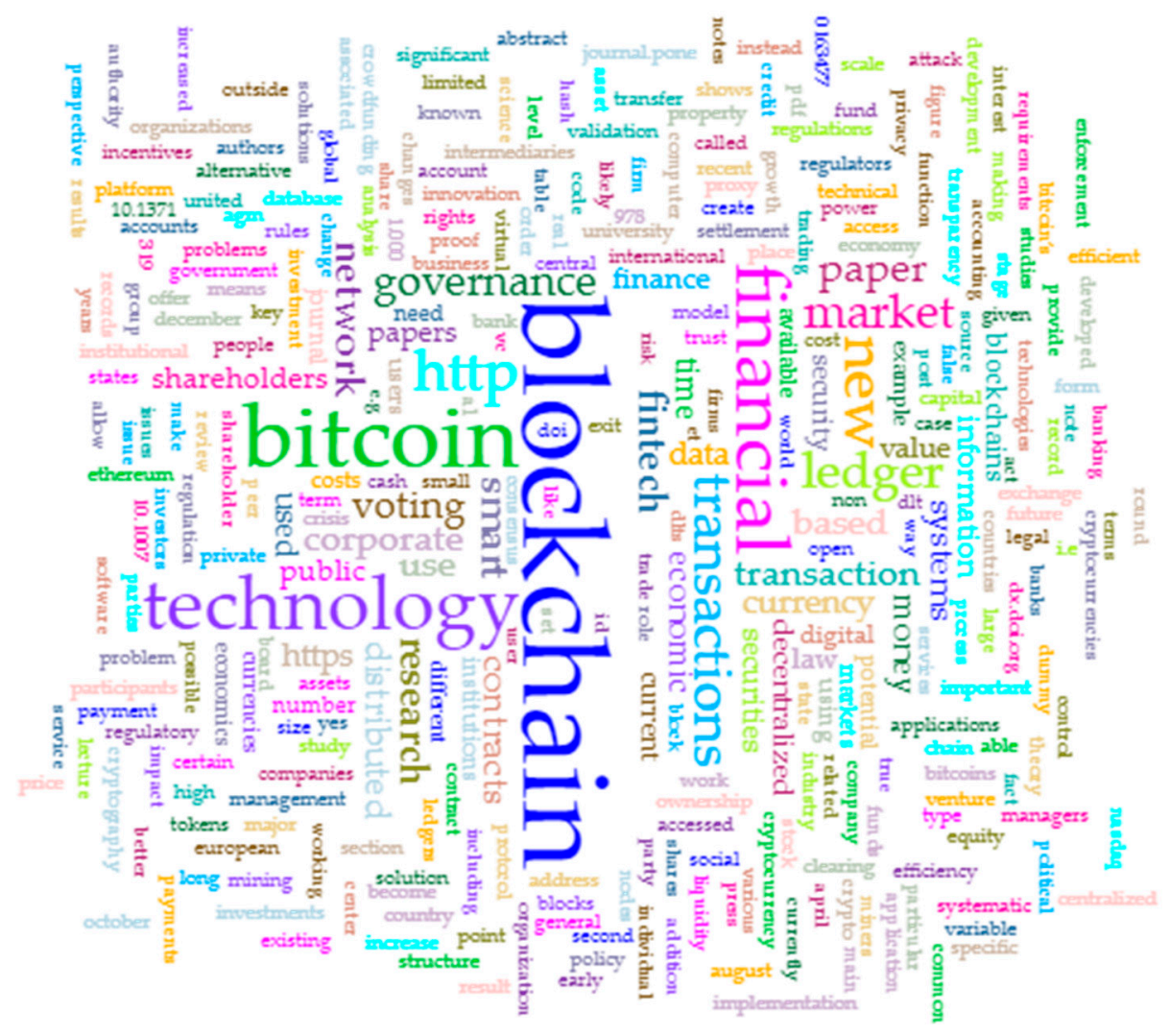

Figure 3. Resource map from textual analysis of both industry and academic literature.

Figures 4 and 5 display resource maps for academic and industry literature separately. By comparing key themes identified in Figures 4 and 5 we again explore the differences, similarities and gaps between academic and industry literature. Figure 5 depicts 1 . blockchain, 2. Bitcoin, 3. technology, 4. financial, 5. transactions, 6. network, 7. fintech, 8. governance, 9. markets and 10. ledger as key themes in the academic literature. Meanwhile, Figure 5 shows 1. blockchain, 2. markets, 3. technology, 4. business, 5. global, 6. privacy, 7. Bitcoin, 8. industry, 9. transactions, 10. bank, 11. currencies and 12. fintech as key themes from industry reports. By comparing these themes, we can identify that both industry and academic literature can be largely concentrated on 1. Bitcoin, 2. markets, 3. technology and 4. fintech. This shows the preferred blockchain-based areas in Bitcoin, blockchains in markets, technology of blockchains itself and use of blockchain as a financial technology. However, the industry and academic interests diverge in the following cases: industry focuses on 1. privacy, 2. business and 3. global, and academia focuses on 1. governance, 2. networks and 3. ledger. Giving context to these themes would enable us to observe that industry focuses more on blockchain potential on a global scale, with business applications and features of blockchain such as privacy. However, the academic literature is relatively narrower by exploring blockchain governance and blockchain architecture with regard to its networks and the decentralised nature of blockchains. 


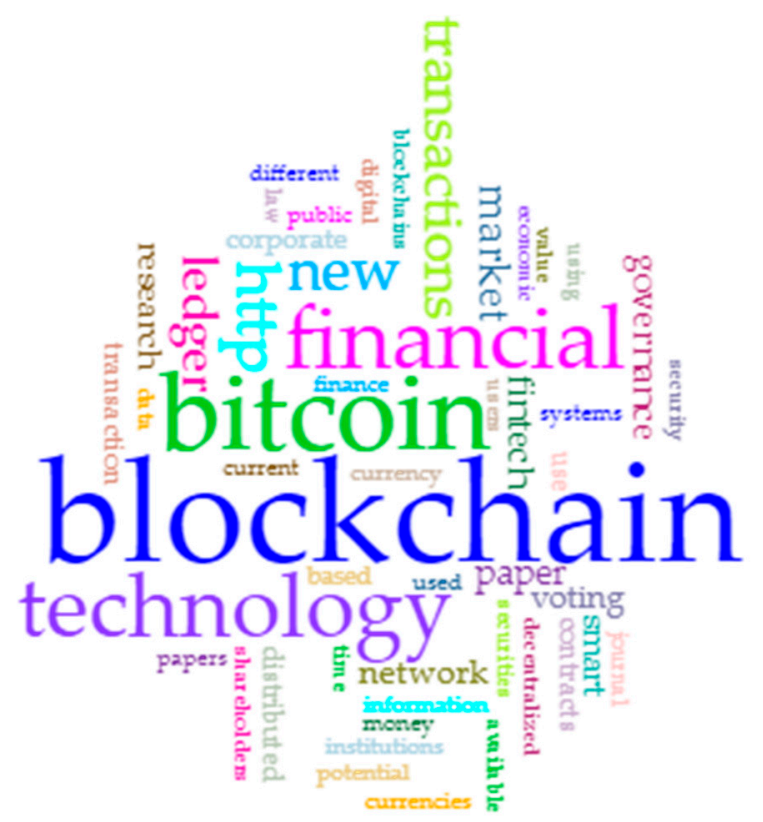

Figure 4. Resource map from textual analysis of academic literature.

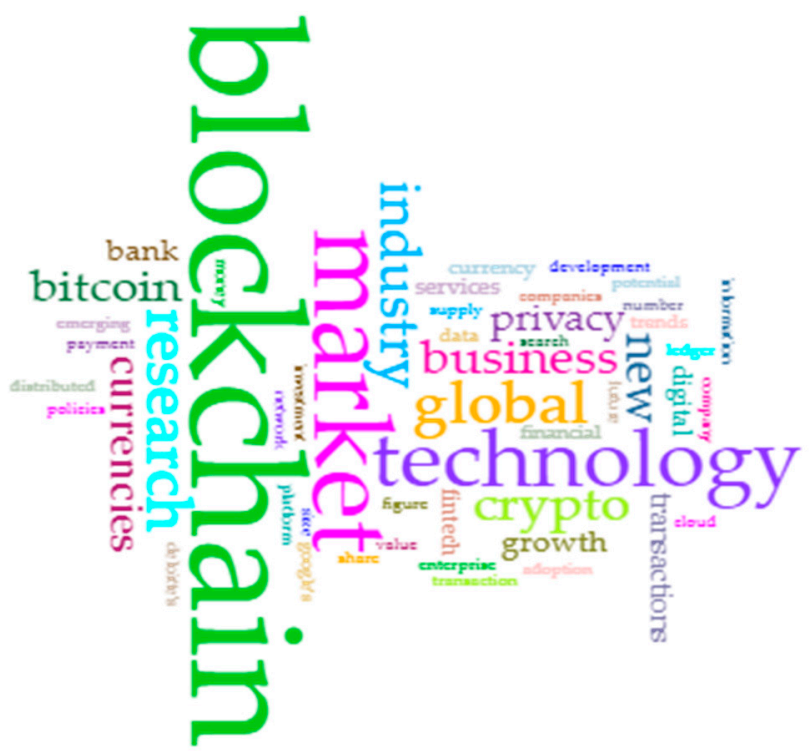

Figure 5. Resource map from textual analysis of industry literature.

\subsection{Decentralized Autonomous Corporate Governance (DACG) Framework}

In essence, blockchain is a distributed ledger (which can be open, permissioned or private) that records transactions in a permanent verifiable manner among parties efficiently. In some platforms, these tasks can be programmed to trigger transactions automatically given certain contingencies (smart contracts). With blockchain-enabled corporate governance, need for intermediaries such as brokers, banks and lawyers would be significantly reduced. Instead, stakeholders, users, organizations and blockchains would transact and communicate with each other with as little friction as possible. Such a newly digitized world of corporate governance, which may seem decades away into the future, is the daunting potential of blockchains. Moreover, due to COVID-19, that future may come more sooner than anticipated. Figure 6 outlines our DACG framework. 


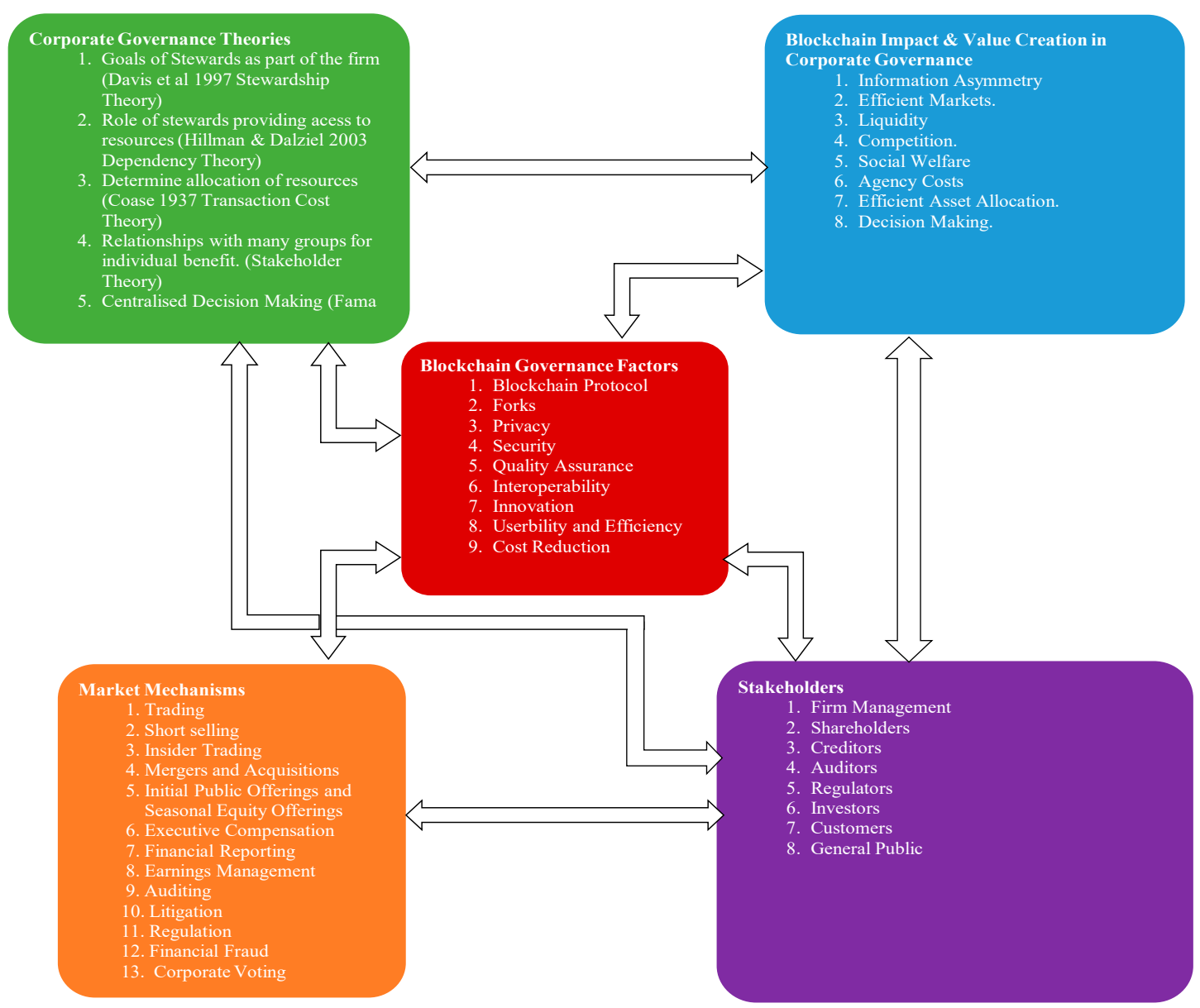

Figure 6. Decentralized autonomous corporate governance.

Key features of the blockchain technology are already deeply embedded in our economic, legal and political systems in terms of record-keeping, transactions, contracts and stakeholders. Similar to the functions in a blockchain, organizational governance and boundaries are established as is verification of ownership, identities, recordkeeping of events and interactions among stakeholders. Hence, in our opinion, application of blockchain into corporate governance is just another form of digitizing the same factors in corporate governance. However, the possibility of digitization at every level may pose several ethical, regulatory and social issues apart from key advantages. These issues and advantages are discussed in the later sections of this study. The DACG Framework is designed to help organizations and interested parties achieve clarity, ensure value from their efforts, create a clear mission, maintain scope and focus and establish accountabilities with regard to blockchain adoption in corporate governance. This section of the paper describes the key components and core factors of the DACG Framework. In essence, this framework provides an overview of blockchains, its impact and relevant corporate governance applications and theories to enable proper adoption.

\subsubsection{Why Use the DACG Framework?}

Most transactions of an organization revolve around the following key drivers: profit maximization, manage complexities and costs, risk management, security and privacy. All efforts of an organisation would ultimately revolve around these three core mandates. However, maintaining focus on all factors and keeping all aspects in mind may be difficult, especially when trying to explore the feasibility and potential adoption of a new technology such as blockchains. Given this setting, our framework helps interested parties and organisations to keep the bigger picture in mind. Frameworks enable us to organize how we envision and communicate about ambiguous, new and complicated concepts. 
Thus, a proper framework at a higher level on the impact of blockchain adoption can provide clarity and purpose for interested stakeholders. Our framework has five main components: corporate governance theories, market mechanisms, blockchain impact, stakeholders and finally, at the centre, blockchain governance. The key themes in our framework are explained in detail below.

\subsubsection{Corporate Governance Theories Relevant to Blockchain Adoption}

One contribution of our study is to survey prior literature on corporate governance theories and identify theories that are related to blockchain adoption and explore their subsequent impact. Table 3 explains these theories and impact of blockchain adoption in more detail. Identification of such theories is important to fully understand the potential and implications of blockchain adoption and develop new theories related to blockchain adoption in corporate governance. To this end, we have identified these key theories in corporate governance. 1. Goals of stewards as part of the firm (Davis et al. 1997, Stewardship Theory). 2. Role of stewards providing access to resources (Hillman and Dalziel 2003, Dependency Theory). 3. Determining allocation of resources (Coase 1937, Transaction Cost Theory). 4. Relationships with many groups for individual benefit. (Stakeholder Theory). 5. Centralized decision making (Fama and Jensen 1983 Agency Costs).

Table 3. Blockchain Adoption Implications and Corporate Governance Theories.

\begin{tabular}{|c|c|c|}
\hline Corporate Governance Theory & Theory Description & Blockchain Adoption Implications \\
\hline \multicolumn{3}{|c|}{ 1. Shares of a corporation would be issued and held on a blockchain } \\
\hline Agency costs & $\begin{array}{l}\text { The primary goal of good governance in firms is to } \\
\text { protect shareholders and other stakeholders from the } \\
\text { managerial discretion }\end{array}$ & $\begin{array}{l}\text { 1. Increased transparency and subsequent reduced } \\
\text { information asymmetry would significantly change incentives } \\
\text { and profit opportunities for managers. }\end{array}$ \\
\hline Transaction cost theory & $\begin{array}{l}\text { The organization and structure of a firm can } \\
\text { determine price and production. }\end{array}$ & $\begin{array}{l}\text { 1. Reduced cost and speed of execution would greatly } \\
\text { improve liquidity, and information incorporation into asset } \\
\text { prices would facilitate high frequency. } \\
2 \text {. It would increase demand for investments in stocks and } \\
\text { also create new investing strategies, objectives and dynamics. } \\
\text { 3. The real-time archiving of trades would result in } \\
\text { information being incorporated into prices more speedily, } \\
\text { making markets more efficient }\end{array}$ \\
\hline Stewardship theory & $\begin{array}{c}\text { Stewards are company executives and managers } \\
\text { working and protecting and making money for } \\
\text { the shareholders. }\end{array}$ & $\begin{array}{l}\text { 1. It would reduce information asymmetry and would } \\
\text { significantly change incentives and profit opportunities for } \\
\text { institutional investors, insiders and other traders in general }\end{array}$ \\
\hline Political theory & $\begin{array}{l}\text { Considers the approach of developing voting } \\
\text { support from shareholders, rather than by } \\
\text { purchasing voting power }\end{array}$ & \\
\hline \multicolumn{3}{|c|}{ 2. Corporate Voting } \\
\hline Agency costs & $\begin{array}{l}\text { The primary goal of good governance in firms is to } \\
\text { protect shareholders and other stakeholders from the } \\
\text { managerial discretion. }\end{array}$ & $\begin{array}{l}\text { 1. Voters and the firm would be able to see that votes had been } \\
\text { cast validly, but if desired, would not be able to see how } \\
\text { particular voters voted. This in turn would greatly increase the } \\
\text { cost and speed of voting, would increase accuracy and would } \\
\text { reduced interference by management. }\end{array}$ \\
\hline Transaction cost theory & $\begin{array}{l}\text { The organization and structure of a firm can } \\
\text { determine price and production. }\end{array}$ & \\
\hline
\end{tabular}




\subsubsection{Blockchain Impact and Value Creation}

This section is an amalgamation of our identification of the bridge between prior academic research and industry reports on blockchain applications in corporate governance. This key theme was developed by identifying the characteristics, advantages and disadvantages of present and future use case applications of blockchain adoption in corporate governance through our systematic review, then linking these to value creation avenues in terms of prior academic literature and market mechanisms that are affected by blockchain adoption in corporate governance. These key factors include the following: 1. Information asymmetry-blockchain offers transparency. 2. Efficient markets-blockchain offers higher speed, efficiency, lesser agency costs and transparency. 3. Liquidity-blockchain can handle large amounts of data with ease and efficiency and more transparency. 4. Competition-blockchain allows more participation. 5. Social welfare-blockchains would result in lesser agency costs, frauds and mismanagement. 6. Agency costs-removal or reduction of agents in blockchains results in lesser agency costs. 7. Efficient asset allocation-increased speed, efficiency and transparency and more efficient markets would result in efficient resource allocation. 8. Decision-making-blockchain would result in better decision making due to lesser agency costs, more transparency and efficient markets.

\subsubsection{Stakeholders}

This section synthesizes the stakeholders involved in blockchain adoption in corporate governance. This identification is fundamental to the understanding and implementation of blockchain adoption with regard to corporate governance. The key factors in this section include 1. firm management. 2. shareholders. 3. creditors. 4. auditors. 5. regulators. 6. investors. 7. customers and general public.

\subsubsection{Market Mechanisms}

This section identifies the market mechanisms that would be affected by blockchain adoption in corporate governance. The key factors include 1. trading, 2. short selling, 3. insider trading, 4. mergers and acquisitions, 5. initial public offerings and seasonal equity offerings, 6 . executive compensation, 7. financial reporting, 8. earnings management, 9. auditing, 10. Litigation, 11. Regulation, 12. financial fraud and 13. corporate voting.

\subsubsection{Blockchain Governance}

Finally, at the centre of the framework lies the blockchain governance section that is linked to all other sections. Without proper governance of blockchains, its adoption in any area would not be sustainable long term. Therefore, this section includes the following key blockchain governance factors: 1. blockchain protocol, 2. forks, 3. Privacy, 4. Security, 5. quality assurance, 6. Interoperability, 7. Innovation, 8. usability and efficiency and 9. cost reduction. To ensure efficient, ethical and sustainable blockchain adoption in corporate governance, it is important to understand all themes and factors identified in our DACG framework.

\subsection{Empirical Analysis}

This section answers Research Question 5: What are the links between investments in blockchain internationally and future forecasts? Table 4 outlines blockchain wallet users in millions with numbers increasing to 44.69 million users in the 2019 fourth quarter, showing demand interest increasing. A significant increase in users can be observed between the first and second quarter in 2019 to reflect the Bitcoin price fluctuations, trade war fears between U.S. and China and growing interest in cryptocurrencies.

From the supply side, Figure 7 depicts the number of venture rounds completed between 2017 and the end of February 2018 led or participated in by key investors in blockchain and innovative technologies. It identifies several key venture capital firms monopolising investments in blockchain technologies in financial markets. Figure 8 depicts the percentage of blockchain and related startups 
for several key countries between 2017 and the end of February 2018. The U.S. is leading investments in blockchain and related startups. The majority of the "other" percentage is due to China.

Table 4. Number of Blockchain Wallet users.

\begin{tabular}{cc}
\hline Year & Number of Blockchain Wallet Users in Millions \\
\hline 2016 Q3 & 8.95 \\
2016 Q4 & 10.98 \\
2017 Q1 & 12.89 \\
2017 Q2 & 14.97 \\
2017 Q3 & 17.26 \\
2017 Q4 & 21.51 \\
2018 Q1 & 23.95 \\
2018 Q2 & 25.76 \\
2018 Q3 & 28.89 \\
2018 Q4 & 31.91 \\
2019 Q1 & 34.66 \\
2019 Q2 & 40.09 \\
2019 Q3 & 42.31 \\
2019 Q4 & 44.69 \\
\hline
\end{tabular}

Source: Statista.

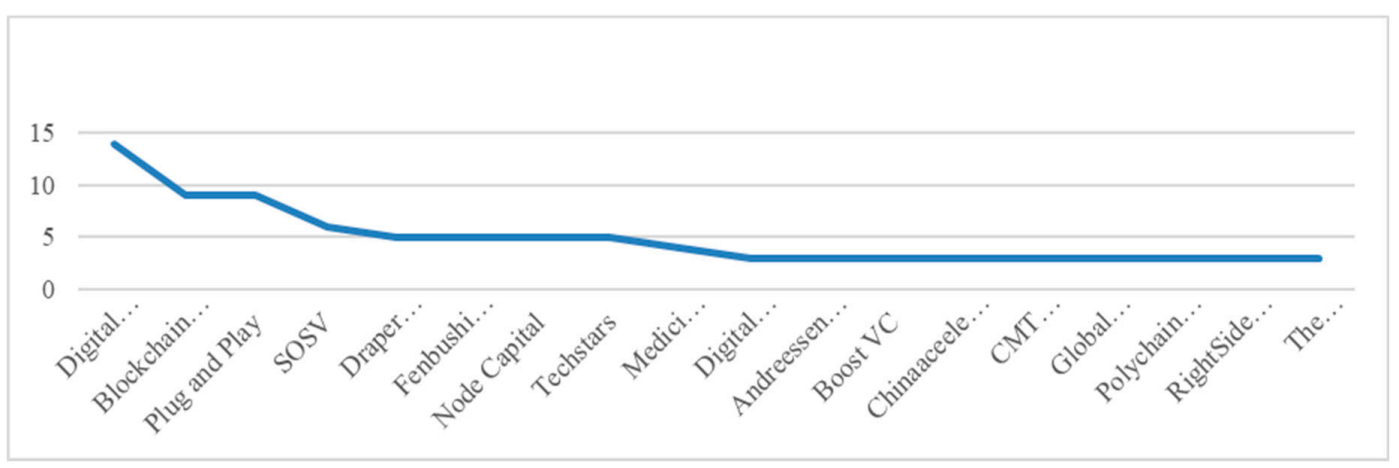

Figure 7. Venture round count completed by key investors of blockchain between 2017 and end of February 2018. Source: CB insights, PwC, ICO Insights and Token Data.

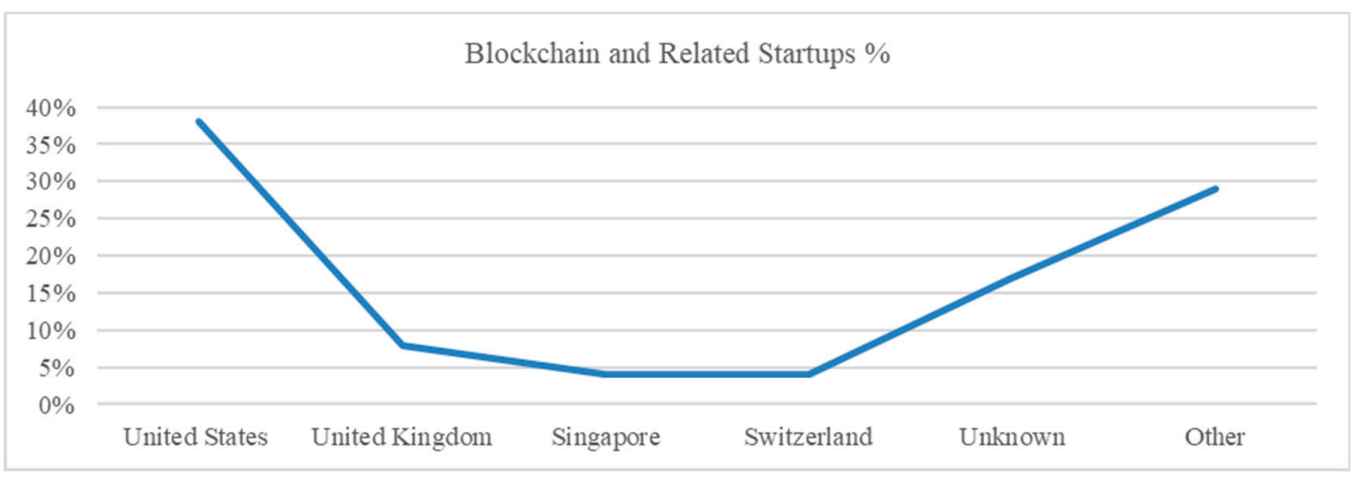

Figure 8. Percentage of Blockchain and related start-ups by geography between 2017 and end of February 2018. Source: CB insights, PwC, ICO Insights and Token Data.

Figure 9 depicts blockchain technology investment by different categories. According to Figure 9 , the majority of blockchain investments are applications related to Bitcoin, with the highest and third-highest investments being in bitcoin exchanges and Bitcoin-based financial services. The second highest investment is in innovations in blockchain platforms. It is concerning to observe the low investments in blockchain big data, where developments would be made in handling the large amount of data maintained on blockchains. Figure 10 depicts the number of investments in each blockchain 
category. This supports the picture provided in Figure 9 with numerous Bitcoin-related applications monopolizing developments with regard to blockchain technology.

The quarterly data for the sample period 2013 to 2019, for Table 5 and Figures 11 and 12, are collected from CB insights, Hutt Capital, $\mathrm{PwC}$, ICO Insights and Token Data. There is negative correlation between European blockchain investments and those of Asia (largely driven by China). Table 5 provides the correlation of investments in blockchains between global investments, U.S., Europe and Asia. There is negative correlation between European blockchain investments and those of Asia (largely driven by China). There is strong correlation between global blockchain investments and Asia showing a co-movement of optimistic sentiment in blockchains and the massive investments by China.

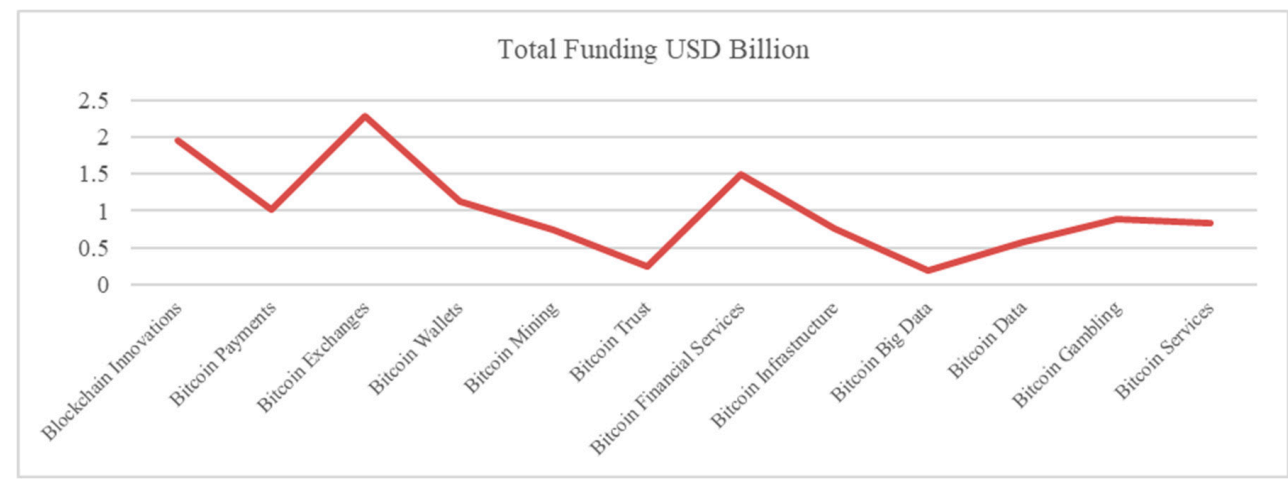

Figure 9. Blockchain Technology investment by different categories. Source: $\mathrm{CB}$ insights, PwC, ICO Insights and Token Data.

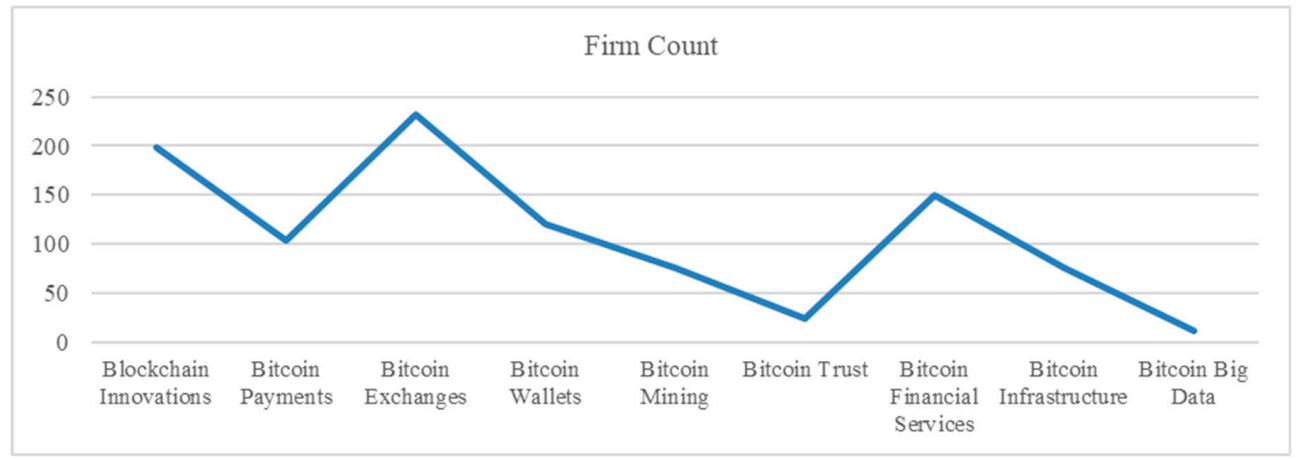

Figure 10. Number of blockchain technology deals by different categories. Source: CB insights, PwC, ICO Insights and Token Data.

Table 5. Correlations of quarterly investments in fintech between global investment, U.S., Europe and Asia from 2013 to 2019.

\begin{tabular}{cc}
\hline Region & Correlation \\
\hline Global and U.S. & 0.22 \\
Global and Europe & 0.20 \\
Global and Asia & 0.94 \\
U.S. and Europe & 0.11 \\
U.S. and Asia & 0.16 \\
Europe and Asia & -0.15 \\
\hline
\end{tabular}

Source: Calculated by the authors using CB insights, Hutt Capital, PwC, ICO Insights and Token Data sources.

We used average linear extrapolation to forecast future investments and blockchain deal counts globally. Figures 11 and 12 both exhibit a growing linear trend for investments and deal counts in 2020 and 2021, reaching 6.173 and 6.051 USD billion and 822 and 937, respectively despite the COVID-19 crisis. This is expected, as with lockdowns and social distancing measures expected to be in place 
for the foreseeable future, most firms are driven to digital transformations where blockchain is a key technology. In addition, with increased investment from China in the BSN and the race to implement digital currencies by central banks in several countries including the U.S., increases in blockchain investments are expected to further increase globally.

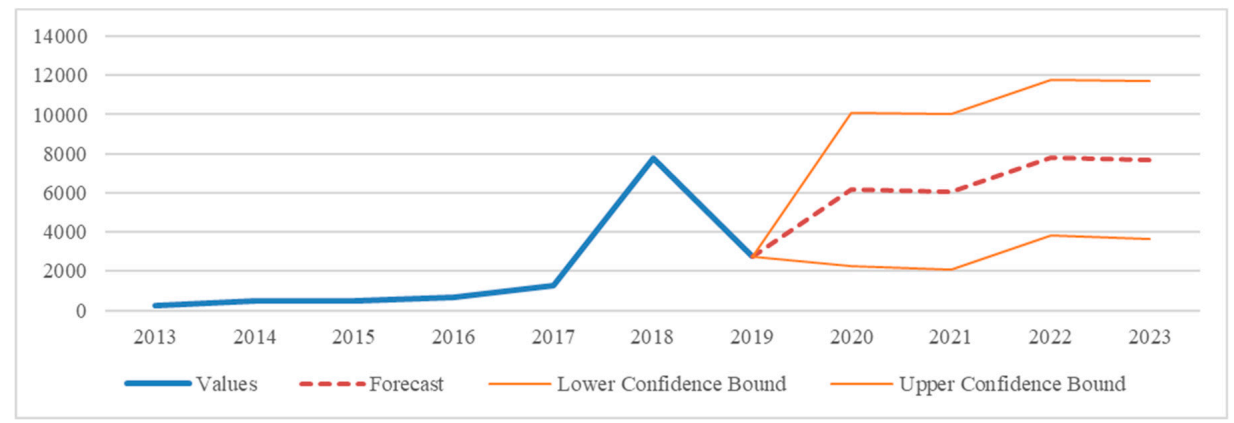

Figure 11. Venture capital investments in blockchain technology and future investment forecasts (\$ million). Source: Calculated by the authors based on quarterly data from 2013 to 2019 using CB insights, Hutt Capital, PwC, ICO Insights and Token Data sources.

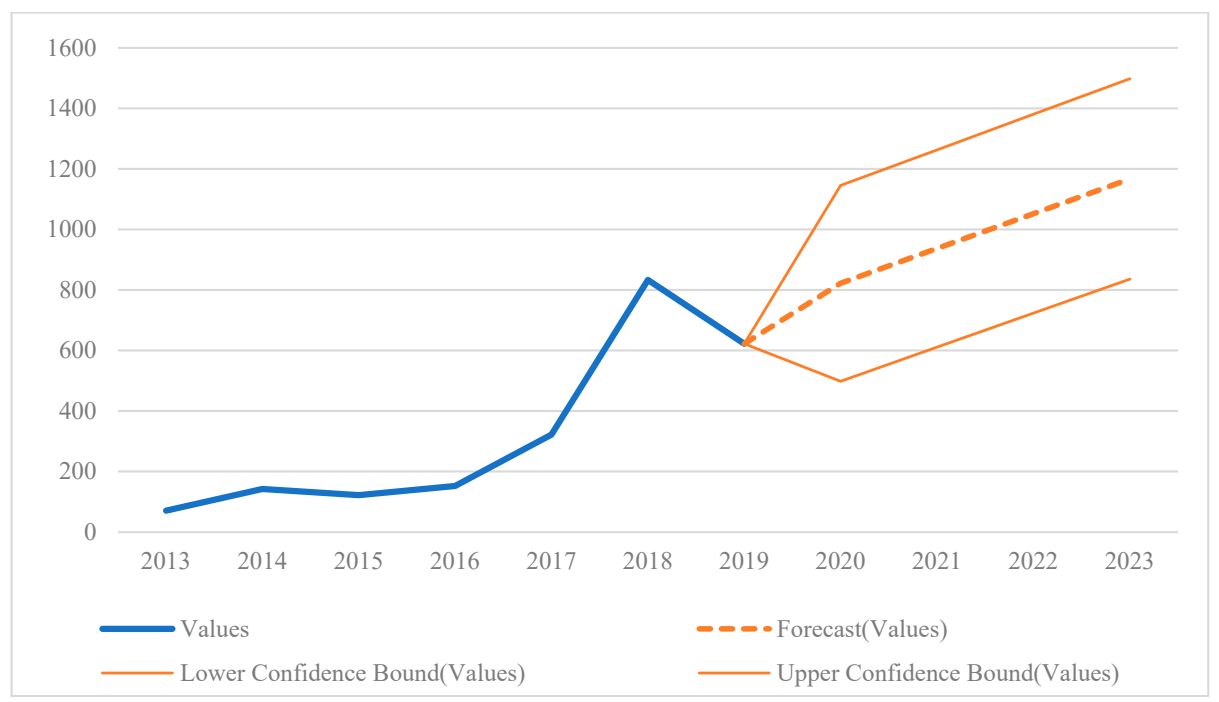

Figure 12. Number of deals by venture capital firms in blockchain technology and future deal count forecasts. Source: Calculated by the authors using CB insights, Hutt Capital, PwC, ICO Insights and Token Data.

\section{Blockchain Adoption in Corporate Governance}

This section answers our Research Question 1: What are the current and future use cases of blockchain applications in corporate governance? We discuss applications of blockchain by financial institutions, accounting and taxation and initial coin offerings in two other studies. The work by stock exchanges around the world on blockchain is particularly significant. They signal that tokenization of shares will occur sooner rather than later. The key implementations of blockchain in clearing houses and securities exchanges are provided in Table 6.

Moving exchanges to blockchain platforms would reduce information redundancies, costs and speed of transactions, subsequently improving performance (Mathew and Irrera 2017). However, a common risk with regard to blockchains is the issues of security of private keys (Mathew and Irrera 2017). These are proofs of ownership which can be stolen. In our opinion, multi-signature transactions where signatures of all parties are required before agreement to a transaction may circumvent this issue. Table 7 provides a summary of the implications of blockchain adoption in corporate governance to various market mechanisms and market participants based on prior literature and our opinion. 
Table 6. Present Blockchain Applications in Corporate Governance.

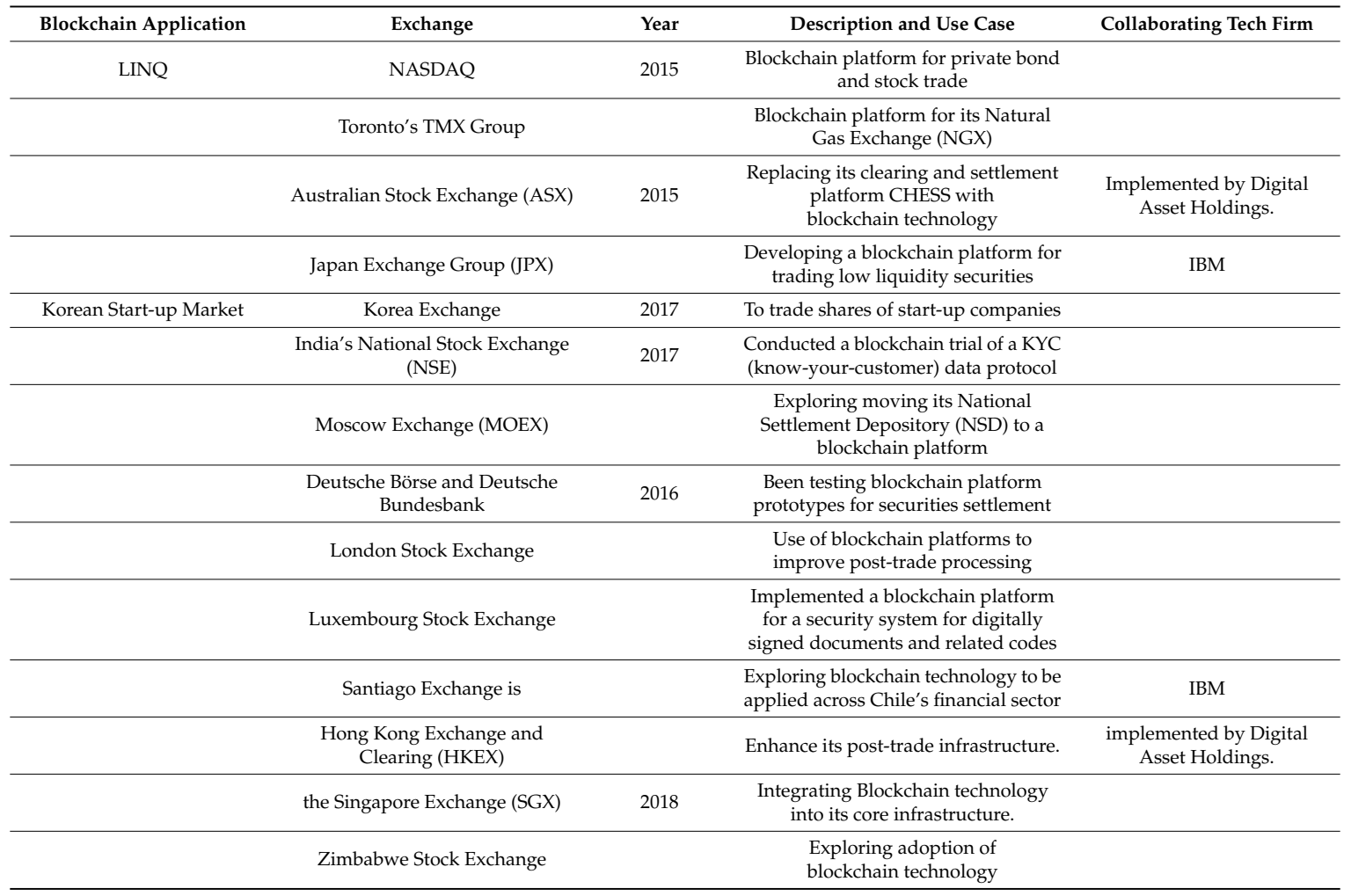

Table 7. Stakeholders and Blockchain Adoption Implications in Corporate Governance.

\begin{tabular}{cl}
\hline \multicolumn{1}{c}{ Stakeholders } & \multicolumn{1}{c}{ Behavioural Perspectives of Blockchain Adoption } \\
\hline 1. Market Mechanisms & $\begin{array}{l}\text { Mergers where building hostile positions for takeovers may be hindered and blockchains may become a part of } \\
\text { takeover defence mechanisms. }\end{array}$ \\
\hline 2. Shareholders & $\begin{array}{l}\text { Whilst shareholders might become more passive, similar to what is discussed in Grossman and Hart's (1980) free-rider } \\
\text { problem, it is more likely that the increased transparency that blockchains offer may change and even expand the role } \\
\text { of shareholders in corporate governance. This may also hinder board of directors' and managers' decision-making, } \\
\text { especially if interrupted by shareholders with no expertise in the relevant field. }\end{array}$ \\
\hline $\begin{array}{c}\text { 3. New Breed of Third-Party } \\
\text { Identity Verification Firms }\end{array}$ & $\begin{array}{l}\text { Even if aliases are used for share purchases, third parties could earn fees for ascertaining the identity of shareowners. } \\
\text { These third parties would build upon the existing mechanisms used in financial markets to identify certain traders } \\
\text { based on observed sequences, size and timing of trades. }\end{array}$ \\
\hline 4. Intermediaries and Exchanges & $\begin{array}{l}\text { Blockchains could reduce settlement times to minutes if not seconds, or slightly longer if public blockchains are used, } \\
\text { and without the need for intermediaries. }\end{array}$ \\
\hline 5. Insiders & $\begin{array}{l}\text { Insiders'/managers' buy order trades result in significant and stronger market reactions as opposed to sell orders } \\
\text { (Brochet (2010)). Blockchains would enable easier differentiation of informed trading, subsequently increasing the } \\
\text { information content and absorption into asset prices. }\end{array}$ \\
\hline 6. Retail Investors & $\begin{array}{l}\text { Blockchain, with its increased transparency and (considerably) faster execution, would be available to retail investors. } \\
\text { The advantages previously available to institutional investors may be reduced and the playing field levelled. }\end{array}$ \\
\hline 7. Block Holders & $\begin{array}{l}\text { The reduction in costs especially for selling shares via increased liquidity would enhance block holder exits and would } \\
\text { increase block holders' power over managers (Edmans (2014)). The increased threat of exit by block holders would } \\
\text { result in managers pursuing shareholder-value-maximizing projects and deter them from projects with private benefits } \\
\text { (Admati and Pfleiderer (2009)). }\end{array}$ \\
\hline
\end{tabular}

\subsection{Firm Share Tokenization}

This article explores the effects of blockchain adoption in the corporate governance sphere such as the tokenisation of a corporation's shares. Tokenisation involves placing shares onto a blockchain and the resulting consequences and opportunities. Blockchain could provide unprecedented transparency to market participants to identify the ownership positions and transactions of debt, equity investors and insiders (managers) (Primm 2016). This would decrease moral hazard, fraud and errors by firms, exchanges and regulators alike (Kahan and Rock 2008). The tokenisation of shares allows for increased efficiency, specifically in terms of accuracy and timeliness of shareholder voting, payment of dividends and a myriad of other uses including limiting empty voting (Accenture 2017). Lee (2016) states that blockchain technology has advantages such as cost execution speed and settlement time reduction. 
The ability to observe trading transactions historically, as well as in real-time, reduces information asymmetry and would significantly change incentives and profit opportunities for institutional investors, insiders and other traders in general (Primm 2016). In our opinion, securities may be designed to better utilize the ability of smart contracts to be executed autonomously. There are, however, legal issues with the tokenisation of a corporations' shares, which are not discussed in this study. Schroeder (2015) explores the legal implications of virtual assets existing on blockchains, classifying them as uncertificated securities under Article 8 of the Uniform Commercial Code. Other implications of blockchain adoption would be spillovers to mergers and acquisitions. Even market mechanisms such as mergers where building hostile positions for takeovers may be hindered, and blockchains may become a part of takeover defence mechanisms (Schroeder 2015), whilst shareholders might become more passive, similar to what is discussed in Grossman and Hart's (1980) free-rider problem. In our opinion, it is more likely that increased transparency offered by blockchains may change and even expand the role of shareholders in corporate governance.

Malinova and Park (2017) state that identifying buyers and sellers would benefit markets in general and increase market welfare. Thus, based on this argument, digital identity would be preferred over attempts to hiding identity. In the U.S., stock trades generally take approximately three business days to settle (Malinova and Park 2017). Many parties are involved in these transactions, which occur under the Depository Trust Clearing Houses' supervision. Blockchains could reduce settlement times to minutes if not seconds or slightly longer if public blockchains are used, and without the need for intermediaries (Primm 2016), thus reducing costs and commissions involved. In our opinion, significantly improved liquidity would facilitate high-frequency trading and demand for investments in stocks and create new investing strategies, objectives and dynamics.

Insiders'/managers' buy order trades result in significant and stronger market reactions as opposed to sell orders (Brochet 2010). It is our view that blockchains would enable easier differentiation of informed trading, subsequently increasing the information content and absorption into asset prices. This would be a departure from current market dynamics, where speed of bad news and good news absorption to prices is slow (Hong et al. 2000). Market makers would be able to observe all shares traded by investors. This would increase the quality of information content generated (Accenture 2017), thus leading to more efficient prices and reduced risk premiums (Edmans et al. 2016). We perceive that this would spill over to efficient resource allocation in the real economy and also better decision-making internally at firms.

\subsection{Corporate Elections}

Corporate elections are one of the many ways blockchains can be used in corporate governance. Current corporate elections are often conducted through proxy voting systems. Kahan and Rock (2008) find that present proxy voting systems are flawed as there are erroneous voter lists, incorrect vote tabulations and incomplete ballot distributions. Listokin (2008) identifies close elections as ending up in favor of management choices. Blockchain can be used to implement accurate proxy voting by allocating eligible voters a token or vote coin as a number that represents their voting power (Boucher 2016). Voters and the firm may observe that votes had been cast validly. However, if desired, they would not observe how particular individuals voted. In our opinion, this would greatly increase the speed of voting and accuracy and would reduce cost and interference by management. Moreover, we believe that increased transparency, speed and reduced costs would result in more shareholder and other interested stakeholder participation. Thus, stakeholders may get involved directly in corporate governance and petition for votes on important firm decisions.

\subsection{Empty Voting}

Empty voting involves using borrowed shares or derivative combinations to acquire voting rights on a temporary basis. This mechanism would shield the voter from being exposed to cashflow rights, monitoring or enforcement of those securities (Hu and Black 2006; Christoffersen et al. 2007). Shareholders engage in empty voting to gain immediate profits or for long-term ownership motivations. Using blockchain 
for corporate elections and shares would prove empty voting more difficult or even prevent it entirely (Boucher 2016). Smart contracts can be used to enforce a stand-down period following the transfer of a share, during which time the share is stripped of its voting rights. Table 3 mentioned earlier provides a summary of the implications of blockchain adoption in corporate governance. This table further links blockchain adoption to traditional corporate governance theories in academic literature.

\subsection{Reg Tech and Corporate Governance}

RegTech refers to digitized regulation compliance and has been prevalent since the 1990s. Growing investments in blockchain and wide adoption especially in the financial services industry have picked the interest of regulators on evaluating blockchain's potential in this sphere. Moreover, the global RegTech Market revenue is expected to reach $\$ 7.2$ billion by 2023 (Infoholic Research 2018). However, the majority of existing regulation on blockchain is limited to ICOs, cryptocurrencies and very specific legal issues such as "know your client (KYC)" and "Anti-money-laundering (AML)". The role of RegTech with regard to corporate governance is very clear. Blockchains can provide enhanced security, process digitization, document tracking and internal and external management with regard to regulatory compliance (De Lis 2016). Blockchain has the capability to track and monitor compliance rates at an individual level in a relatively small amount of time. Several RegTech applications track online activities of a firm's employees (Arner et al. 2017). Subsequently, these records compiled can be used to identify adherence to firm rules and other regulations. In addition, these applications can track and monitor irregularities in documents, employee activities and create incident reports (Deloitte 2016).

\section{Blockchain Governance and Ethical Aspects}

Governance of blockchains is a key issue. Public blockchains are governed autonomously by software code. The code specifies inputs, the priority and timing and limits the sizes or contingencies associated with encoding every transaction into the blockchain (Atzori 2015). These parameters of governance in a blockchain are similar to the regulations specified by stock exchanges for listed firms. Most corporations that are exploring blockchain projects are using permissioned blockchains such as a permissioned version of Ethereum. However, even in permissioned blockchains, governance rules would need to be negotiated and renegotiated, similar to partnerships or other customized financial contracts (Paech 2017). Beck et al. (2018) provide an excellent discussion on blockchain governance from a DAO case study perspective. Table 8 summarizes present regulation of blockchain technology in several selected countries.

\section{Ethical Aspects of Blockchain}

A key relevance of blockchains to financial markets is its immutability (Papadopoulos 2015), thus limiting or removing a firm managements' ability to influence accounting records and other business transactions ex-post. Fraudulent activities such as using employee stock options to extract private benefits at the shareholder's expense by backdating the option date when price levels are lowest (Bray and Mathews 2011) would be mitigated by blockchain adoption. It is our view that the high level of transparency provided by blockchain would reveal more high-quality information and increased speed to shareholders. This in turn would increase firm management accountability to shareholders, regulators and other market participants. Tapscott and Tapscott (2017) argue that blockchains introduce a novel sphere of business integrity of transparency, honesty, consideration and accountability, which in turn would result in better accurate pricing of executive compensation and asset prices in general. Ultimately, blockchains may shift power from firm management towards shareholders, employees and regulators (Yermack 2017).

In addition, blockchains can help solve coordination, verification, authentication and enforcement issues. For example, extremely high transaction costs and many breaches of the law go unnoticed. Even if such breaches are identified, it is often too late, with substantial damage already ensured (Brummer 2015). Finally, in our view, an overlooked feature of blockchain is its potential in preventing wrongdoing. For example, instead of designing a regulatory system to attempt to prevent empty 
voting, empty voting can be prevented as follows: shares can be in effect programmed so that following the sale of a share, it is stripped of voting rights for a set period; nor would an individual be able to borrow a share and vote using that particular share.

Table 8. Global Regulation of Blockchains.

\begin{tabular}{cl}
\hline Country & \multicolumn{1}{c}{ Regulation } \\
\hline United States & $\begin{array}{l}\text { Enacted state laws on smart contracts, blockchain-based digital signatures and legal admissibility of blockchain ledgers } \\
\text { as evidence. }\end{array}$ \\
\hline Russia & Announced a regulatory framework for ICOs. \\
\hline France & Allows crowdfunding records to be kept on blockchain ledgers. \\
\hline United Kingdom & Started to allow sandboxes for certain fintech products including blockchains. \\
\hline Switzerland and Luxembourg & Announced similar sandboxing initiatives to the United Kingdom. \\
\hline Australia & $\begin{array}{l}\text { The International Organization for Standardization (ISO) has set up a task force working on these internal blockchain } \\
\text { standards and also on standards about the interoperability of separate blockchains. }\end{array}$ \\
\hline China & Prohibition of crypto-currencies/taskforces on blockchain. \\
\hline Japan & Reports/declarations/taskforce. \\
\hline India & Reports/statements of intent to regulate. \\
\hline Turkey & Taskforces on blockchains. \\
\hline Singapore & AML regulation on c-currencies/taskforce on blockchain. \\
\hline Canada & Reports/taskforces/sandboxing. \\
\hline
\end{tabular}

\section{Blockchain Adoption and Corporate Governance during the COVID-19 Crisis}

This section answers our Research Question 4: What are the advantages of blockchain adoption in corporate governance during and post-COVID-19? With an ongoing major worldwide health outbreak challenging and disrupting firms, individuals and many social aspects, corporate governance digitalization becomes increasingly important. Blockchains can play a central role in this setting. In our opinion, blockchain technology may be used to record firm data and ensure these data sources are transparent and traceable within each firm to effectively reduce errors, processing times and smooth firm administration. Thus, blockchains would provide management with a platform, to track progress of projects in real-time, and employees can register the relevant data on to the chain securely. The data links based on transparent monitoring and increased security via blockchains would result in an increase in accountability by employees and other stakeholders linked to the firm. This would further reduce mismanagement, security risks and errors during lockdowns and working-from-home environments. Moving firms day-to-day operations and transactions onto a blockchain platform would aid in corporate boards having better oversight. With blockchain platforms updated in real time, boards would possess increased visibility of business operations and better understand the risks faced by the firm and the impact of the ever-evolving pandemic situation, thus resulting in improved day-to-day and strategic decision-making. Additionally, blockchains can facilitate efficient coordination of information sharing, planning, implementation and communication to employees and other stakeholders.

Moreover, the pandemic has highlighted the fragilities in the traditional financial markets and fiat currencies, with many advocating for digital currencies. Cryptocurrency is a key theme of blockchain applications and is relevant to corporate governance as identified by our study. Two major reasons behind this renewed interest in digital or crypto currencies stem from inflation of traditional fiat currencies and the decrease in interest rates of traditional assets such as bank deposits. Thus, the ongoing COVID-19 pandemic has accelerated the development of central bank digital currencies. For example, the People's Bank of China has already completed basic function development for a digital yuan. Moreover, the development of Blockchain-based Service Network (BSN), which is backed by an alliance of Chinese state-owned firms, government agencies, banks and technology firms further highlight the importance of corporate governance with regard to blockchains. The BSN is expected to reduce the costs of doing blockchain-based business in China by $80 \%$. Alibaba subsidiary Ant Financial also grabbed the spotlight by announcing its new consortium chain called Open Chain. The COVID-19 outbreak is a common challenge faced by businesses across the world. Thus, blockchain can be the new tool for corporate governance to overcome this unprecedented disruption for our way of conducting business and traditional corporate governance. 


\section{Limitations of Our Study}

This section discusses several limitations of our study. With regard to the empirical analysis section, a major limitation is the small sample period of 2012 to 2020. Most firms are secretive in their nature on investment breakdown into new technologies. Thus, it is difficult to obtain investments only relating to blockchains. Another limitation is that of sample selection bias, which can occur in systematic reviews due to distortions in the search and selection criteria. In order to overcome this issue, we used various permutations of our search topics, backtracked from key words in other survey articles on blockchain unrelated to finance and used refinements in our search databases. In addition, we further perused the reference lists of articles selected to identify relevant articles (snowball effect). Inconsistent coding of themes may be another limitation of our study. Thus, we supplemented our manual review process through textual analysis and by carefully re-assessing the articles in our final sample manually with special focus on the abstract, keywords, introduction and conclusion.

\section{Conclusions}

Blockchain technology has great potential to provide efficient solutions to many issues that adversely affect current systems in corporate governance. However, several issues of permissioned versus public blockchains, capital required, possibilities of hacking, lack of extensive research and understanding, to name a few, still persist. Our study differs from its contemporaries by systematically reviewing prior scattered literature, conducting a textual and empirical analysis to develop a framework for blockchain adoption in corporate governance, differentiating between industry and academic literature over time and key themes and forecasting future investments. In addition, our study provides a behavioural and ethical perspective to blockchain adoption in corporate governance. A systematic review of 851 records and a final article sample of 183 for the sample period 2012 to 2020 resulted in the identification of nine primary themes from prior literature with relevance to blockchain adoption in corporate governance. Academic articles mostly focus on regulation (49 studies) and ICOs (46 studies), while industry articles primarily focus on exchanges (10 studies) and cryptocurrencies ( 9 articles). Significant growth in academic and industry literature is observed for 2017 (48 studies) and 2018 (42 studies) in aggregate.

Through our textual analysis, we identified that the industry and academic literature pursue common themes, such as 1. Bitcoin, 2. markets, 3. technology and 4. fintech related to blockchain. However, their interests diverge, where industry focuses more on 1. privacy, 2. business and 3. Global, and the academia concentrates on 1. governance, 2. networks and 3. ledger. Based on our empirical analysis, we forecast investments and deal counts in blockchain for 2020 and 2021 reaching up to 6.173 and 6.051 USD billion and 822 and 937, respectively. Finally, we conclude that with regard to corporate governance, permissioned blockchains may still be used to limit transparency, yet absolute transparency may cause unwarranted shareholder panic. Thus, firms would most likely implement different accessibility levels. A key question is whether regulators should allow firms to limit transparency. Blockchains may result in better corporate governance models with higher accuracy, accessibility and efficiency, resulting in improved decision making by shareholders. Smart contracts on blockchains in the future can provide novel ways of governing corporates. However, as highlighted by this study, such progression should go hand-in-hand with the corresponding regulatory developments. Moreover, COVID-19 environment driving most firms to digital transformation including China's massive investments in Blockchain technology (BSN) and the digitalisation of the Yuan and interest in blockchains is most likely to further increase significantly in the future.

Author Contributions: The authors contributed equally to the article. All authors have read and agreed to the published version of the manuscript.

Funding: This research received no external funding.

Conflicts of Interest: The authors declare no conflict of interest. 


\section{Appendix A}

Table A1. Comparison of literature between industry, academic studies and professional bodies.

\begin{tabular}{|c|c|c|c|c|c|c|c|c|c|}
\hline \multirow[b]{2}{*}{$\begin{array}{l}\text { Industry } \\
\text { Academia }\end{array}$} & \multirow{2}{*}{$\begin{array}{c}\text { Exchanges \& CG } \\
10\end{array}$} & \multirow{2}{*}{$\begin{array}{c}\text { Corporate Voting \& CG } \\
3\end{array}$} & \multirow{2}{*}{$\begin{array}{c}\text { Practice and Education of } \mathbf{B C} \\
2\end{array}$} & \multirow{2}{*}{$\begin{array}{c}\text { BC \&CG } \\
1\end{array}$} & \multirow{2}{*}{$\begin{array}{c}\text { Regulation } \\
6\end{array}$} & \multirow{2}{*}{$\frac{\text { BC Technology }}{3}$} & \multirow{2}{*}{$\begin{array}{c}\text { ICOs \& Crowd Funding } \\
5\end{array}$} & \multicolumn{2}{|c|}{ Crypto-Currencies Other } \\
\hline & & & & & & & & 9 & 1 \\
\hline Abadi and Brunnermeier (2018) & & & 1 & & & 1 & & & 1 \\
\hline Abramowicz (2016) & & & & & 1 & & & 1 & \\
\hline Adhami et al. (2018) & & & & & 1 & & 1 & 1 & \\
\hline Aggarwal and Stein (2016) & & & 1 & & 1 & & 1 & & \\
\hline Amsden and Schweizer (2018) & & & & & & & 1 & & \\
\hline Aoyagi and Adachi (2018) & & & & & & 1 & & 1 & 1 \\
\hline Arner et al. (2017) & & & & & 1 & & & & \\
\hline Ante et al. (2018) & & & & & & & 1 & & \\
\hline An et al. (2019) & & & & & & & 1 & & \\
\hline Asharaf and Adarsh (2017) & & & & & & 1 & & & 1 \\
\hline Atzei et al. (2017) & & & & & & 1 & & 1 & 1 \\
\hline Atzori (2015) & & & & & 1 & 1 & & 1 & 1 \\
\hline Babich and Hilary (2019) & & & & & & 1 & & & 1 \\
\hline Barefoot (2015) & & & & & 1 & & & & \\
\hline Badertscher et al. (2017) & 1 & & & & & 1 & & 1 & \\
\hline Bagby et al. (2018) & & & & & 1 & & & & 1 \\
\hline Bakos and Halaburda (2018) & & & & & & & 1 & 1 & 1 \\
\hline Barber et al. (2012) & & & & & & 1 & & 1 & \\
\hline Barsan (2017) & & & & & 1 & & & & \\
\hline Bebchuk and Jackson (2012) & 1 & & & & 1 & & & & 1 \\
\hline Benedetti and Kostovetsky & & & & & & & 1 & & \\
\hline Blaseg (2018) & & & & & & & 1 & & \\
\hline Böhme et al. (2015) & 1 & & & 1 & & 1 & & & \\
\hline Boucher (2016) & & 1 & & & & 1 & & & 1 \\
\hline Bourveau et al. (2019) & 1 & & & & & & 1 & 1 & \\
\hline Braggion et al. (2020) & & & & & & & & & \\
\hline Brenig et al. (2015) & & & & & 1 & & & 1 & \\
\hline Brainard (2016) & 1 & & & & 1 & 1 & & & \\
\hline Brummer (2015) & 1 & & & & 1 & & & & \\
\hline Butenko and Larouche (2015) & & & & & 1 & & & & \\
\hline Buterin (2014) & & & & & & 1 & 1 & & 1 \\
\hline Catalini and Gans (2016) & 1 & & 1 & & & & & & \\
\hline Catalini and Gans (2018) & & & & & 1 & & & 1 & 1 \\
\hline Carvalho (2020) & & & & & & 1 & & & \\
\hline Chemla and Tinn (2017) & & & & & & & 1 & & \\
\hline Chen et al. (2019) & & & & 1 & & & & & 1 \\
\hline Chen (2018) & & & & & & 1 & 1 & & 1 \\
\hline Chiu and Greene (2018) & & & & & & & 1 & & 1 \\
\hline Christensen et al. (2015) & & & & & & 1 & 1 & & 1 \\
\hline Chod and Lyandres (2018) & & & 1 & & 1 & & 1 & & \\
\hline Chohan (2017) & & & & & 1 & & 1 & & \\
\hline
\end{tabular}


Table A1. Cont.

\begin{tabular}{|c|c|c|c|c|c|c|c|c|}
\hline & Exchanges \& CG & Corporate Voting \& CG & Practice and Education of $\mathrm{BC}$ & BC \&CG & Regulation & BC Technology & ICOs \& Crowd Funding & Crypto-Currencies Othe \\
\hline Clements (2018) & & & & & & & 1 & 1 \\
\hline Cocco et al. (2017) & & & 1 & & & & & \\
\hline Cohen et al. (2017) & 1 & & & & 1 & & & \\
\hline Collomb et al. (2018) & & & & & & & 1 & 1 \\
\hline Cong and $\mathrm{He}$ (2019) & & & 1 & 1 & & 1 & & \\
\hline Cong et al. (2020) & & & & & & 1 & 1 & 1 \\
\hline Conley (2017) & & & & & & & 1 & 1 \\
\hline Cortez (2014) & & & & & 1 & & & 1 \\
\hline Da Rin and Penas (2017) & & & & & & & & 1 \\
\hline Dapp (2014) & & & & & & & & 1 \\
\hline Davidson et al. (2016) & & & & & 1 & & & \\
\hline Dean et al. (2019) & & & & & & & & 1 \\
\hline Deer et al. (2015) & & & & & & & & 1 \\
\hline Filippi and Hassan (2016) & & & & & 1 & & & 1 \\
\hline De Filippi and Wright (2018) & & & & & & & & 1 \\
\hline De Lis (2016) & & & & & & & & 1 \\
\hline Deng et al. (2018) & & & & & & & 1 & \\
\hline de Reuver et al. (2018) & & & 1 & & & & & \\
\hline Dierksmeier and Seele (2018) & & & & & 1 & & & \\
\hline Drobetz et al. (2019) & & & & & & & 1 & \\
\hline DuPont (2017) & & & & 1 & & & & \\
\hline Easley et al. (2017) & & & & 1 & & & & 1 \\
\hline Eyal and Sirer (2018) & & & & & & 1 & & 1 \\
\hline Evans (2014) & & & & & 1 & 1 & & \\
\hline Fanning and Centers (2016) & & 1 & & & & & & \\
\hline Feng et al. (2018) & & & & & & & 1 & \\
\hline Fenwick et al. (2018) & & & & & 1 & & & 1 \\
\hline Felix and Eije (2019) & & & & & & & 1 & 1 \\
\hline Fichman and Zheng (2014) & & & 1 & & & & & 1 \\
\hline Fisch (2018) & & & & & & & 1 & \\
\hline Foley et al. (2019) & & & & & 1 & & & 1 \\
\hline Frame and White (2014b) & & & 1 & & & & & 1 \\
\hline Gomber et al. (2017) & & & & & & & & 1 \\
\hline Goldstein et al. (2019) & & 1 & & & & & & \\
\hline Governatori et al. (2018) & & & & & 1 & & & \\
\hline Graglia and Mellon (2018) & & & & & & & & 1 \\
\hline Harwick (2016) & & & & & 1 & & & 1 \\
\hline (Hileman and Rauchs 2017) & & & & & & & & \\
\hline Holden and Moar (2017) & & & & & & & & 1 \\
\hline Houy (2014) & 1 & & & & & 1 & & \\
\hline Howell et al. (2018) & & & & 1 & & & 1 & 1 \\
\hline Hsieh et al. (2017) & & & & 1 & & 1 & 1 & 1 \\
\hline Hughes and Middlebrook (2015) & & & & & 1 & & & 1 \\
\hline Jayasuriya and Sims (2019) & & & 1 & & 1 & & & \\
\hline Kaal (2016) & & & & & 1 & & & \\
\hline Kaal and Vermeulen (2017) & & & & & 1 & & & 1 \\
\hline Kaal and Dell'Erba (2017) & & & & & 1 & & 1 & \\
\hline
\end{tabular}


Table A1. Cont.

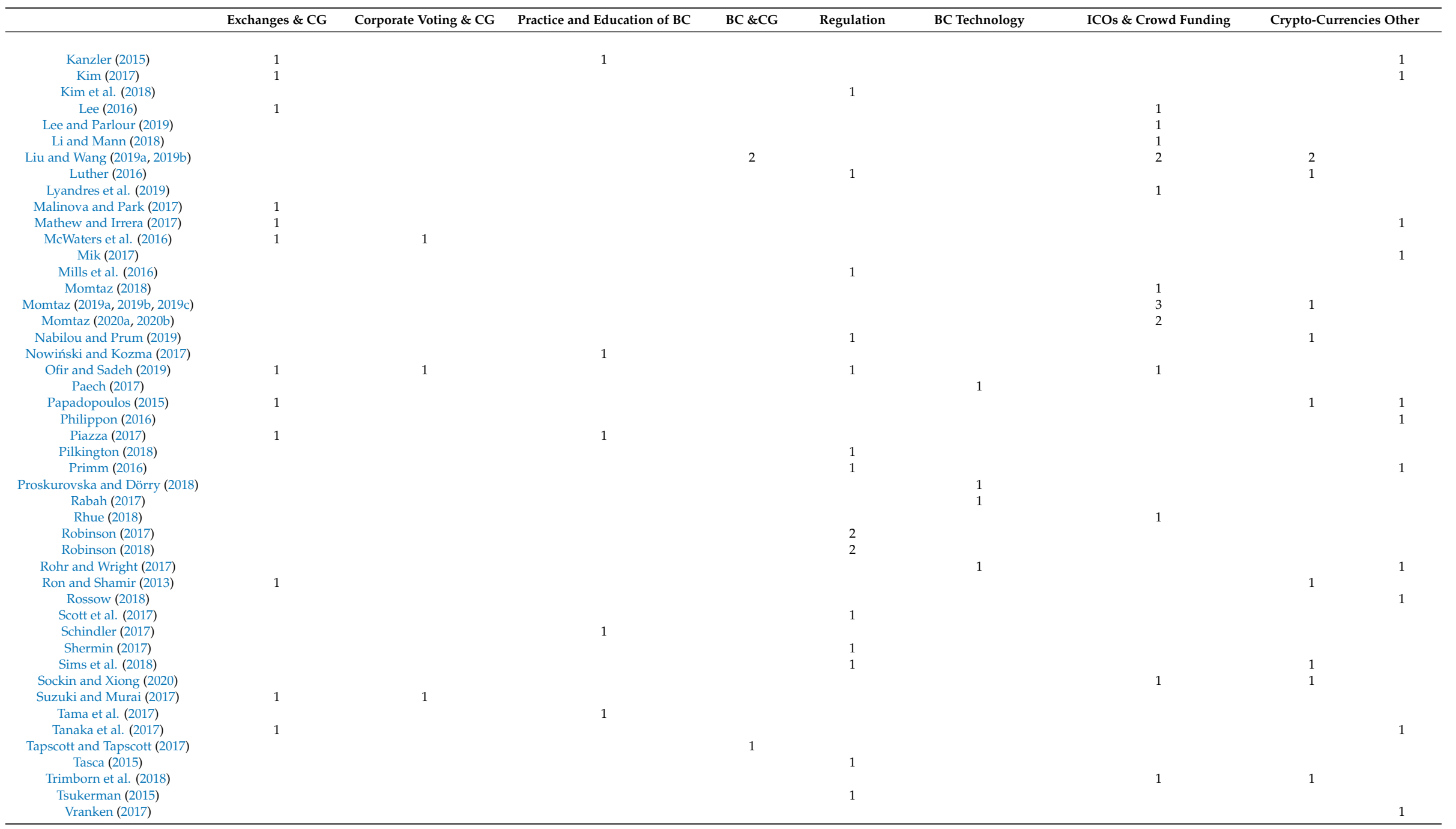


Table A1. Cont.

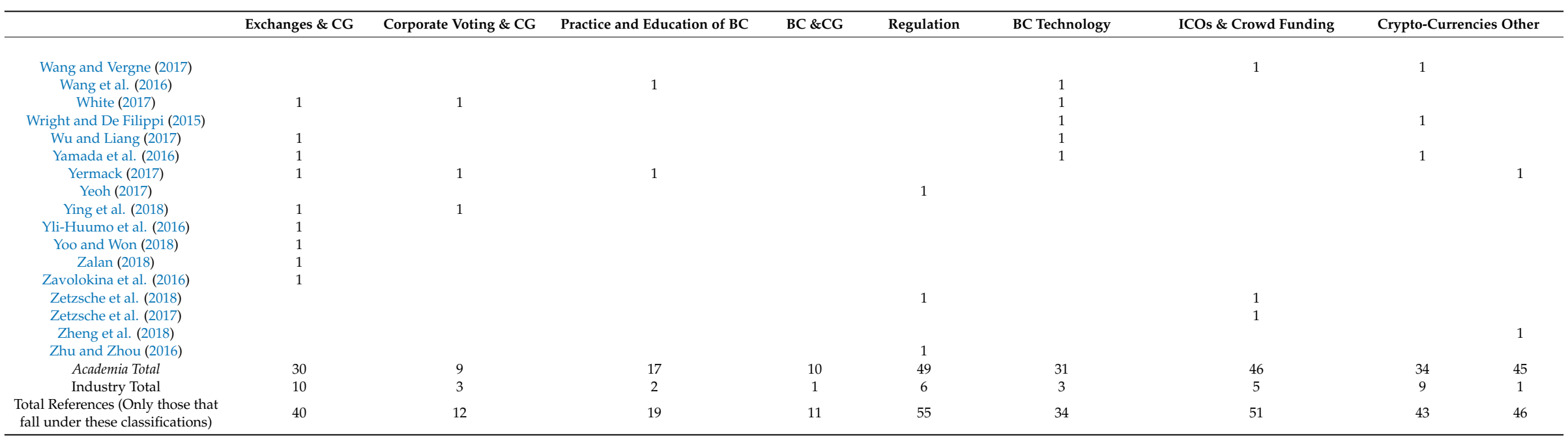




\section{References}

Abadi, Joseph, and Markus Brunnermeier. 2018. Blockchain Economics (No. w25407). National Bureau of Economic Research. Available online: https://www.nber.org/papers/w25407 (accessed on 1 June 2020).

Abramowicz, Michael. 2016. Cryptocurrency-Based Law. Arizona Law Review 58: 359-420. Available online: http://arizonalawreview.org/cryptocurrency-based-law/ (accessed on 1 June 2020).

Accenture. 2017. Banking on Blockchain. In A Value Analysis for Investment Banks. Dublin: Accenture.

Adhami, Saman, Giancarlo Giudici, and Stefano Martinazzi. 2018. Why do Businesses Go Crypto? An Empirical Analysis of Initial Coin Offerings. Journal of Economics and Business 100: 64-75. [CrossRef]

Admati, Anat R., and Paul Pfleiderer. 2009. The 'Wall Street Walk' and Shareholder Activism: Exit as a Form of Voice. The Review of Financial Studies 22: 2645-85. [CrossRef]

Aggarwal, Reena, and Peer Stein. 2016. The Complex Regulatory Landscape for FinTech: An Uncertain Future for Small and Medium-Sized Enterprise Lending. Cologny: World Economic Forum.

Aguilera, R Ruth V., and Alvaro Cuervo-Cazurra. 2009. Codes of Good Governance. Corporate Governance: An International Review 17: 376-87. [CrossRef]

Ahlering, Beth, and Simon Deakin. 2007. Labour Regulation, Corporate Governance and Legal Origin: A Case of Institutional Complementarity? Law \& Society Review 41: 865-908.

Allan, Gareth, and Yuki Hagiwara. 2018. Bitcoin Futures Get Cold Shoulder From Japanese Regulator. New York: Bloomberg, Available online: https:/www.bloomberg.com/news/articles/2018-01-24/bitcoin-futures-getcold-shoulder-from-japan-financial-regulator (accessed on 1 June 2020).

Amsden, Ryan, and Denis Schweizer. 2018. Are Blockchain Crowdsales the New "Gold Rush"? Success Determinants of Initial Coin Offerings. In Proceedings of the Decentralized Identity Foundation Conference, Chiemsee, Germany, May 16. [CrossRef]

An, Jiafu, Tinghua Duan, Wenxuan Hou, and Xinyu Xu. 2019. Initial Coin Offerings and Entrepreneurial Finance: The Role of Founders' Characteristics. The Journal of Alternative Investments 21: 26-40. [CrossRef]

Ante, Lennart, Sandner G. Philip, and Ingo Fiedler. 2018. Blockchain-based ICOs: Pure Hype or the Dawn of a New Era of Startup Financing? Journal of Risk and Financial Management 11: 80. [CrossRef]

Aoyagi, Jun, and Daisuke Adachi. 2018. Economic Implications of Blockchain Platforms. arXiv arXiv:1802.10117. Arner, Douglas W., Janos Nathan Barberis, and Ross P. Buckley. 2017. FinTech, RegTech and the Re-Conceptualization of Financial Regulation. Northwestern Journal of International Law and Business 37: 371-413.

Asharaf, S., and S. Adarsh. 2017. Decentralized Computing Using Blockchain Technologies and Smart Contracts: Emerging Research and Opportunities. Hershey Pennsylvania: IGI Global.

Atzei, Nicola, Massimo Bartoletti, and Tiziana Cimoli. 2017. A Survey of Attacks on Ethereum Smart Contracts (SoK). In Proceedings of the International Conference on Principles of Security and Trust, Uppsala, Sweden, April 22-29; pp. 164-86. [CrossRef]

Atzori, Marcella. 2015. Blockchain Technology and Decentralized Governance: Is the State Still Necessary? Available online: https://doi.org/10.2139/ssrn.2709713 (accessed on 1 June 2020).

Babich, Volodymyr, and Gilles Hilary. 2019. Distributed Ledgers and Operations: What Operations Management Researchers Should Know About Blockchain Technology. Manufacturing E Service Operations Management 22: 223-428. [CrossRef]

Badertscher, Christian, Ueli Maurer, Daniel Tschudi, and Vassilis Zikas. 2017. Bitcoin as a Transaction Ledger: A Composable Treatment. In Proceedings of the Annual International Cryptology Conference, Santa Barbara, CA, USA, August 20-24; Cham: Springer, pp. 324-56. [CrossRef]

Bagby, John W., David Reitter, and Philip Chwistek. 2018. An Emerging Political Economy of the Blockchain: Enhancing Regulatory Opportunities. Available online: https://ssrn.com/abstract=3299598 (accessed on 1 June 2020).

Bakos, Yannis, and Hanna Halaburda. 2018. The Role of Cryptographic Tokens and ICOs in Fostering Platform Adoption. Available online: https://papers.ssrn.com/sol3/papers.cfm?abstract_id=3207777 (accessed on 1 June 2020).

Barber, Simon, Xavier Boyen, Elaine Shi, and Ersin Uzun. 2012. Bitter to Betterhow to Make Bitcoin a Better Currency. Financial Cryptography and Data Security. Berlin/Heidelberg: Springer, pp. 399-414.

Barefoot, Jo Ann S. 2015. Disrupting Fintech Law. Fintech Law Reporter 18: 1-18. 
Barsan, Iris M. 2017. Legal Challenges of Initial Coin Offerings (ICO). Paris: Revue Trimestrielle de Droit Financier (RTDF), pp. 5-65. Available online: https://papers.ssrn.com/sol3/papers.cfm?abstract_id=3064397 (accessed on 1 June 2020).

Bebchuk, Lucian A., and Robert J. Jackson Jr. 2012. The Law and Economics of Blockholder Disclosure. Harvard Business Law Review 2: 39-60. [CrossRef]

Beck, Roman, Michel Avital, Matti Rossi, and Jason Bennett Thatcher. 2017. Blockchain Technology in Business and Information Systems Research. Business and Information Systems Engineering 59: 381384. [CrossRef]

Beck, Roman, Christoph Mueller-Bloch, and John Leslie King. 2018. Governance in the Blockchain Economy: A Framework and Research Agenda. Journal of the Association for Information Systems 19: 1020-34. [CrossRef]

Benedetti, Hugo, and Leonard Kostovetsky. 2018. Digital Tulips? Returns to Investors in Initial Coin Offerings. Returns to Investors in Initial Coin Offerings. Available online: https://papers.ssrn.com/sol3/papers.cfm? abstract_id=3182169 (accessed on 1 June 2020).

Blaseg, Daniel. 2018. Dynamics of Voluntary Disclosure in the Unregulated Market for Initial Coin Offerings. Available online: https://ssrn.com/abstract=3207641 (accessed on 1 June 2020).

Böhme, Rainer, Nicolas Christin, Benjamin Edelman, and Tyler Moore. 2015. Bitcoin: Economics, Technology, and Governance. Journal of Economic Perspectives 29: 213-38. [CrossRef]

Boucher, Philip Nicholas. 2016. What If Blockchain Technology Revolutionized Voting? Luxembourg: European Parliament.

Bourveau, Thomas, Emmanuel T. De George, Atif Ellahie, and Daniele Macciocchi. 2019. Information Intermediaries in the Crypto-Token Market. Available online: https://papers.ssrn.com/sol3/papers.cfm? abstract_id=3193392 (accessed on 1 June 2020).

Braggion, Fabio, Alberto Manconi, and Haikun Zhu. 2020. Can Technology Undermine Macroprudential Regulation? Evidence from Online Marketplace Credit in China. Available online: https://papers.ssrn.com/ sol3/papers.cfm?abstract_id=2957411 (accessed on 1 June 2020). [CrossRef]

Brainard, Lael. 2016. Distributed Ledger Technology: Implications for Payments, Clearing, and Settlement. International Institute of Finance Annual Meeting, Washington, DC, October 7; vol. 7. Available online: https://www.federalreserve.gov/newsevents/speech/brainard20161007a.pdf (accessed on 1 June 2020).

Bray, Alon, and Richmond D. Mathews. 2011. Empty Voting and the Efficiency of Corporate Governance. Journal of Financial Economics 99: 289-307.

Brenig, Christian, Rafael Accorsi, and Günter Müller. 2015. Economic Analysis of Cryptocurrency Backed Money Laundering. In Proceedings of the ECIS, Münster, Germany, May 26-29.

Briner, Rob B., and David Denyer. 2012. Systematic Review and Evidence Synthesis as a Practice and Scholarship Tool. In The Oxford Handbook of Evidence-Based Management. Oxford: Oxford University Press, pp. 112-29.

Briner, Rob B., David Denyer, and Denise M Rousseau. 2009. Evidence Based Management: Concept Cleanup Time? The Academy of Management Perspectives 23: 19-32. [CrossRef]

Brochet, F. 2010. Information Content of Insider Trades Before and After the Sarbanes-Oxley Act. The Accounting Review 85: 419-46. [CrossRef]

Brummer, Chris. 2015. Disruptive Technology and Securities Regulation. Fordham Law Review 84: 977-1051. [CrossRef]

Butenko, Anna, and Pierre Larouche. 2015. Regulation for Innovativeness or Regulation of Innovation? Law, Innovation and Technology 7: 52-82. [CrossRef]

Buterin, Vitalik. 2014. Ethereum White Paper. Available online: http://www.the-blockchain.com/docs/Ethereum white_paper-a_next_generation_smart_contract_and_decentralized_application_platform-vitalik-buterin. pdf (accessed on 1 June 2020).

Cadbury. 1992. Shared Vision and Beyond. Available online: http://wwwdata.unibg.it/dati/corsi/900002/79548Beyond\%20Cadbury\%20Report\%20Napier\%20paper.pdf (accessed on 1 June 2020).

Carvalho, Arthur. 2020. A Permissioned Blockchain-Based Implementation of IMSR Prediction Markets. Decision Support Systems 130: 113228. [CrossRef]

Catalini, Christian, and Joshua S. Gans. 2016. Some Simple Economics of the Blockchain (No. w22952). Cambridge: National Bureau of Economic Research. [CrossRef]

Catalini, Christopher, and Joshua S. Gans. 2018. Initial Coin Offerings and the Value of Crypto Tokens (No. w24418). Cambridge: National Bureau of Economic Research. [CrossRef] 
Chemla, Gilles, and Katrin Tinn. 2017. Learning through Crowdfunding. Management Science 66: 1783-1801. [CrossRef]

Chen, Yan. 2018. Blockchain Tokens and the Potential Democratization of Entrepreneurship and Innovation. Business Horizons 61: 567-75. [CrossRef]

Chen, Mark A., Qinxi Wu, and Baozhong Yang. 2019. How Valuable Is FinTech Innovation? Review of Financial Studies 32: 2062-106. [CrossRef]

Chiu, Iris H.-Y., and Edward Greene. 2018. Can ICO Markets Offer Insights into Marketizing Sustainable or Social Finance? Proposals for a Revolutionary Regulatory Framework. Available online: https://papers.ssrn.com/ abstract_id=3290762 (accessed on 1 June 2020).

Chod, Jiri, and Evgeny Lyandres. 2018. A Theory of ICOs: Diversification, Agency, and Information Asymmetry. Available online: https://ssrn.com/abstract=3159528 (accessed on 1 June 2020).

Chohan, Usman W. 2017. Initial Coin Offerings (ICOs): Risks, Regulation, and Accountability. Discussion Paper Series: Notes on the 21st Century. Available online: https://ssrn.com/abstract=3080098 (accessed on 1 June 2020).

Christensen, Clayton M., Michael E. Raynor, and Rory McDonald. 2015. What Is Disruptive Innovation? Harvard Business Review 93: 44-53.

Christoffersen, Susan E. K., Christopher C. Geczy, David K. Musto, and Adam V. Reed. 2007. Vote Trading and Information Aggregation. Journal of Finance 62: 2897-927. [CrossRef]

Clements, Ryan. 2018. Assessing the Evolution of Cryptocurrency: Demand Factors, Latent Value, and Regulatory Developments. Michigan Business \& Entrepreneurial Law Review 8: 73-97.

Coase, Ronald H. 1937. The Nature of the Firm. Economica 4: 386-405. [CrossRef]

Cocco, Luisanna, Andrea Pinna, and Michele Marchesi. 2017. Banking on Blockchain: Costs Savings Thanks to the Blockchain Technology. Future Internet 9: 25. [CrossRef]

Cohen, Lewis Rinaudo, Lee Samuelson, and Hali Katz. 2017. How Securitization can Benefit from Blockchain Technology. The Journal of Structured Finance 23: 51-54. [CrossRef]

Collomb, Alexis, Primavera De Filippi, and Klara Sok. 2018. From IPOs to ICOs: The Impact of Blockchain Technology on Financial Regulation. Available online: https:/papers.ssrn.com/sol3/papers.cfm?abstract_id= 3185347 (accessed on 1 June 2020).

Cong, Lin William, and Zhiguo He. 2019. Blockchain Disruption and Smart Contracts. The Review of Financial Studies 32: 1754-97. [CrossRef]

Cong, Lin. William, Ye Li, and Neng Wang. 2020. Tokenomics: Dynamic Adoption and Valuation Columbia Business School Research Paper No. 18-46. Available online: https://papers.ssrn.com/abstract=3222802 (accessed on 1 June 2020).

Conley, John. P. 2017. Blockchain and the Economics of Cryptotokens and Initial Coin Offerings. Vanderbilt University Department of Economics No. 17-00008. Nashville: Vanderbilt University Department of Economics, Available online: https://ideas.repec.org/p/van/wpaper/vuecon-sub-17-00007.html (accessed on 1 June 2020).

Cortez, Nathan. 2014. Regulating Disruptive Innovation. Berkeley Technology Law Journal 29: 175-228. [CrossRef]

Da Rin, Marco, and María Fabiana Penas. 2017. Venture Capital and innovation strategies. Industrial and Corporate Change 26: 781-800. [CrossRef]

Dapp, Thomas F. 2014. Fintech-The Digital (r)Evolution in the Financial Sector. Frankfurt: Deutsche Bank Research. Davidson, Sinclair, Primavera De Filippi, and Jason Potts. 2016. Economics of Blockchain. [CrossRef]

Davis, Gerald F., and Tracy A. Thompson. 1994. A Social Movement Perspective on Corporate Control. Administrative Science Quarterly 39: 141-73. [CrossRef]

Davis, James H., F. David Schoorman, and Lex Donaldson. 1997. Toward a Stewardship Theory of Management. The Academy of Management Review 22: 20-47. [CrossRef]

Filippi, Primavera, and Samer Hassan. 2016. Blockchain Technology as a Regulatory Technology: From Code is Law to Law is Code. arXiv arXiv:1801.02507. [CrossRef]

De Filippi, Pilippi, and Aarron Wright. 2018. Blockchain and the Law: The Rule of Code. Cambridge, Massachusetts: Harvard University Press.

De Lis, Santiago Fernández. 2016. RegTech, the New Magic Word in FinTech, Banking Outlook. Madrid: Madrid.

de Reuver, Mark, Carsten Sørensen, and Rahul C. Basole. 2018. The Digital Platform: A Research Agenda. Journal of Information Technology 33: 1-12. [CrossRef] 
Dean, Tobia, D. Dulani Jayasuriya, and Alastair Marsden. 2019. Predictability of ICO Success and Returns. Available online: https://www.arx.cfa/-/media/regional/arx/post-pdf/2019/11/19/predictability-of-ico-successand-returns.ashx? (accessed on 1 June 2020).

Deer, Luke, Jackson Mi, and Yu Yuxin. 2015. The Rise of Peer-To-Peer Lending in China: An Overview and Survey Case Study. London: Association of Chartered Certified Accountants.

Deloitte. 2016. Over the Horizon. Blockchain and the Future of Financial Infrastructure. Available online: https:/www2.deloitte.com/content/dam/Deloitte/nl/Documents/financial-services/deloitte-nl-fsiblockchain-and-the-future-of-financial-infrastructure.pdf (accessed on 1 June 2020).

Deng, Xin, Yen Teik Lee, and Zhengting Zhong. 2018. Decrypting Coin Winners: Disclosure Quality, Governance Mechanism, and Team Networks. Governance Mechanism and Team Networks. Available online: https: //ssrn.com/abstract=3247741 (accessed on 1 June 2020).

Dierksmeier, Claus, and Peter Seele. 2018. Cryptocurrencies and Business Ethics. Journal of Business Ethics 152: 1-14. [CrossRef]

Drobetz, Wolfgang, Paul P. Momtaz, and Henning Schröder. 2019. Investor Sentiment and Initial coin Offerings. The Journal of Alternative Investments 21: 41-55. [CrossRef]

du Plessis, Jean Jacques, Anil Hargovan, and Mirko Bagaric. 2005. Principles of Contemporary Corporate Governance. Melbourne: Cambridge University Press. [CrossRef]

DuPont, Quinn. 2017. Experiments in Algorithmic Governance: A history and Ethnography of "The DAO," A Failed Decentralized Autonomous Organization. In Bitcoin and Beyond. Abingdon: Routledge, pp. 157-75.

Easley, David, Maureen O'Hara, and Soumya Basu. 2017. From Mining to Markets: The Evolution of Bitcoin Transaction Fees. Journal of Financial Economics 134: 91-109. [CrossRef]

Edmans, Alex. 2014. Blockholders and Corporate Governance. Annual Review of Financial Economics 6: 23-50. [CrossRef]

Edmans, Alex, Doron Levit, and Devin Reilly. 2016. Governing Multiple Firms. London: London Business School.

Evans, David S. 2014. Economic Aspects of Bitcoin and Other Decentralized Public-Ledger Currency Platforms. Available online: https://ssrn.com/abstract=2424516 (accessed on 1 June 2020).

Eyal, Ittay, and Emin Gün Sirer. 2018. Majority is not Enough: Bitcoin Mining is Vulnerable. Communications of the ACM 61: 95-102. [CrossRef]

Fama, Eugene F., and Michael C. Jensen. 1983. Separation of Ownership and Control. The Journal of Law and Economics 26: 301-25. [CrossRef]

Fanning, Kurt, and David P. Centers. 2016. Blockchain and its Coming Impact on Financial Services. Journal of Corporate Accounting Finance 27: 53-57. [CrossRef]

Felix, T. H., and H. von Eije. 2019. Underpricing in the Cryptocurrency World: Evidence from Initial Coin Offerings. Managerial Finance 45: 563-78. [CrossRef]

Feng, Chen, Nan Li, M. H. Franco Wong, and Mingyue Zhang. 2018. Initial Coin Offerings, Blockchain Technology, and Voluntary Disclosures. Available online: https://papers.ssrn.com/sol3/papers.cfm?abstract_id=3256289 (accessed on 1 June 2020).

Fenwick, Mark, Wulf A. Kaal, and Erik P. M. Vermeulen. 2018. Regulation Tomorrow: What Happens When Technology Is Faster Than the Law? Lex Research Topics in Corporate Law \& Economics. Available online: https://papers.ssrn.com/abstract_id=2834531 (accessed on 1 June 2020).

Fichman, Robert. Brian L. Dos Santos, and Zhiqiang (Eric) Zheng. 2014. Digital Innovation as a Fundamental and Powerful Concept in the Information Systems Curriculum. Management Information Systems Quarterly 38: 329-43. [CrossRef]

Fisch, Christian. 2018. Initial Coin Offerings (ICOs) to Finance New Ventures: An Exploratory Study. Journal of Business Venturing 34: 1-22. [CrossRef]

Foley, Sean, Jonathan R. Karlsen, and Tālia J. Putninšs. 2019. Sex, Drugs, and Bitcoin: How Much Illegal Activity is Financed through Cryptocurrencies? The Review of Financial Studies 32: 1798-853. [CrossRef]

Frame, W Scott, and Lawrence J. White. 2014b. Technological Change, Financial Innovation, and Diffusion in Banking. In The Oxford Handbook of Banking, 2nd ed. Oxford: Oxford University Press.

Goldstein, Itay, Wei Jiang, and G. Andrew Karolyi. 2019. To FinTech and Beyond. The Review of Financial Studies 32: 1647-61. [CrossRef]

Gomber, Peter, Jascha-Alexander Koch, and Michael Siering. 2017. Digital Finance and FinTech: Current research and Future Research Directions. Journal of Business Economics 87: 537-80. [CrossRef] 
Governatori, Guido, Florian Idelberger, Zoran Milosevic, Regis Riveret, Giovanni Sartor, and Xiwei Xu. 2018. On Legal Contracts, Imperative and Declarative Smart Contracts, and Blockchain Systems. Artificial Intelligence and Law 26: 377-409. [CrossRef]

Graglia, J. Michael, and Christopher Mellon. 2018. Blockchain and Property in 2018: At the End of the Beginning. Innovations: Technology, Governance, Globalization 12: 90-116. [CrossRef]

Grossman, Sanford J., and Oliver D. Hart. 1980. Takeover Bids, the Free Rider Problem, and the Theory of the Corporation. Bell Journal of Economics 11: 42-64. [CrossRef]

Hardy, Robert Augustus, and Julia R. Norgaard. 2016. Reputation in the Internet Black Market: An Empirical and Theoretical Analysis of the Deep Web. Journal of Institutional Economics 12: 515-39. [CrossRef]

Harwick, Cameron. 2016. Cryptocurrency and the Problem of Intermediation. The Independent Review 20: 569-88.

Hileman, Garrick, and Michel Rauchs. 2017. Global Blockchain Benchmarking Study. Cambridge: Cambridge Centre for Alternative Finance.

Hillman, Amy J., Albert A. Cannella, and Romona L. Paetzold. 2000. The Resource Dependence Role of Corporate Directors: Strategic Adaptation of Board Composition in Response to Environmental Change. Journal of Management Studies 37: 235-56. [CrossRef]

Hillman, Amy J., and Thomas Dalziel. 2003. Boards of Directors and Firm Performance: Integrating Agency and Resource Dependence Perspectives. Academy of Management Review 28: 383-96. [CrossRef]

Holden, Windor, and James Moar. 2017. Blockchain Enterprise Survey: Deployments, Benefits \& Attitudes. Hampshire: Juniper Research.

Houy, Nicolas. 2014. The Economics of Bitcoin Transaction Fees. Available online: https://papers.ssrn.com/ abstract_id=2400519 (accessed on 1 June 2020).

Hong, Harrison, Terence Lim, and Jeremy C. Stein. 2000. Bad News Travels Slowly: Size, Analyst Coverage, and the Profitability of Momentum Strategies. Journal of Finance 55: 265-95. [CrossRef]

Howell, Sabrina T., Marina Niessner, and David Yermack. 2018. Initial Coin Offerings: Financing Growth with Cryptocurrency Token Sales (No. w24774). Cambridge: National Bureau of Economic Research. Available online: https://www.nber.org/papers/w24774 (accessed on 1 June 2020).

Hsieh, Ying-Ying, Jean-Philippe Vergne, and Sha Wang. 2017. The Internal and External Governance of Blockchain-Based Organizations: Evidence from Cryptocurrencies. In Bitcoin and Beyond. Abingdon: Routledge, pp. 48-68.

Hu, Henry T. C., and Bernard S Black. 2006. The New Vote Buying: Empty Voting and Hidden (Morphable) Ownership. Southern California Law Review 79: 811-908.

Hughes, Sarah Jane, and Stephen T. Middlebrook. 2015. Advancing a Framework for Regulating Cryptocurrency Payments Intermediaries. Yale Journal on Regulation 32: 495-559.

Humphries, Chris A, and James Smith. 2018. Cayman Islands: Initial Coin Offerings (ICO) In The Cayman Islands. London: Modaq, Available online: http://www.mondaq.com/caymanislands/commoditiesderivativesstockexchanges/667952/initial-coin-offerings-ico-in-the-cayman-islands (accessed on 1 June 2020).

Infoholic Research. 2018. Global Regulatory Technology (RegTech) Market: Drivers, Restraints, Opportunities, Trends, and Forecast up to 2023. Bengaluru: Infoholic Resarch LLP, Available online: https://www.researchandmarkets. com/reports/4614548/global-regulatory-technology-regtech-market\#pos-0 (accessed on 1 June 2020).

Jayasuriya, D. Dulani, and Alexandra Sims. 2019. From the Abacus to Enterprise Resource Planning: Is Blockchain the Next Big Accounting Technology? Unpublished Working Paper.

Jensen, Michael C. 1993. The Modern Industrial Revolution, Exit, and the Failure of Internal Control Systems. The Journal of Finance 48: 831-80. [CrossRef]

Kaal, Wulf A. 2016. Dynamic Regulation for Innovation, Perspectives in Law, Business E Innovation. U of St. Thomas (Minnesota) Legal Studies Research Paper No. 16-22. New York: Springer.

Kaal, Wulf A., and M. Dell'Erba. 2017. Initial Coin Offerings: Emerging Practices, Risk Factors, and Red Flags. Available online: https://papers.ssrn.com/abstract_id=3067615 (accessed on 1 June 2020).

Kaal, Wulf A., and Erik P. M. Vermeulen. 2017. How to Regulate Disruptive Innovation-From Facts to Data. Jurimetrics 57: 169-209. [CrossRef]

Kahan, Marcel, and Edward B. Rock. 2008. The Hanging Chads of Corporate Voting. Georgetown Law Journal 96: 1227-81. 
Kanzler, Viktor. 2015. How Do Fintech Startups and a Changing Consumer Behaviour Reshape the Financial Services Industry? Bachelor's thesis, Frankfurt School of Finance and Management, Frankfurt am Main, Germany.

Kim, T. 2017. On the transaction cost of bitcoin. Finance Research Letters 23: 300-5. [CrossRef]

Kim, Seoyoung, Atulya Sarin, and Daljeet Virdi. 2018. Crypto-Assets Unencrypted. Available online: https: //papers.ssrn.com/sol3/papers.cfm?abstract_id=3117859 (accessed on 1 June 2020).

Lee, Larissa. 2016. New Kids on the Blockchain: How Bitcoin's Technology Could Reinvent the Stock Market. Hastings Business Law Journal 12: 81-132. [CrossRef]

Lee, Jeongmin, and Christine A. Parlour. 2019. Consumers as Financiers: Crowdfunding, Initial Coin Offerings and Consumer Surplus. Working Paper. Available online: https://papers.ssrn.com/abstract_id=3300297 (accessed on 1 June 2020).

Li, Jiasun, and William Mann. 2018. Initial Coin Offering and Platform Building. Available online: https://papers.ssrn.com/abstract_id=3088726 (accessed on 1 June 2020).

Listokin, Yair. 2008. Management Always Wins the Close Ones. American Law and Economics Review 10: $159-84$. [CrossRef]

Liu, Chen, and Haoquan Wang. 2019a. Crypto Tokens and Token Offerings: An Introduction. In Cryptofinance and Mechanism of Exchange: The Making of Virtual Currency. Edited by Stéphane Goutte, Khaled Guesmi and Samir Saadi. Boston: Springer.

Liu, Chen, and Haoquan Wang. 2019b. Initial Coin offerings (ICOs): What do we Know and What are the Success Factors? In Cryptofinance and Mechanism of Exchange: The Making of Virtual Currency. Edited by Stéphane Goutte, Khaled Guesmi and Samir Saadi. Boston: Springer.

Luther, William J. 2016. Cryptocurrencies, Network Effects, and Switching Costs. Contemporary Economic Policy 34: 553-71. [CrossRef]

Lyandres, Evengy, Berardino Palazzo, and Daniel Rabetti. 2019. Do Tokens Behave Like Securities: An Anatomy of Initial Coin Offerings. Available online: https://papers.ssrn.com/abstract_id=3287583 (accessed on 1 June 2020).

Malinova, Katya, and Andreas Park. 2017. Market Design for Trading with Blockchain Technology. Available online: https://papers.ssrn.com/abstract_id=2785626 (accessed on 1 June 2020).

Mathew, Susan, and Anna Irrera. 2017. Australia's ASX Selects Blockchain to Cut Costs. Toronto: Reuters.

McWaters, Jesse, Rob Galaski, and Soumak Chatterjee. 2016. The Future of Financial Infrastructure: An Ambitious Look at How Blockchain Can Reshape Financial Services. Cologny: World Economic Forum.

Mik, Eliza. 2017. Smart Contracts: Terminology, Technical Limitations and Real World Complexity. Law, Innovation and Technology 9: 269-300. [CrossRef]

Mills, David, Kathy Wang, Brendan Malone, Anjan Ravi, Jeff Marquardt, Clinto Chen, Anton Badev, Timothy Brezinski, Linda Fahy, Kimberley Liao, and et al. 2016. Distributed Ledger Technology in Payments, Clearing, and Settlement; Finance and Economics Discussion Series 2016-095; Washinton: Federal Reserve Board of Governors. [CrossRef]

Moher, David, Alessandro Liberati, Jennifer Tetzlaff, and Douglas G. Altman. 2009. Preferred Reporting Items for Systematic Reviews and Meta-analyses: The PRISMA statement. PLoS Medicine 6: e1000097. [CrossRef]

Momtaz, Paul P. 2018. Initial Coin Offerings. Available online: https://papers.ssrn.com/sol3/papers.cfm?abstract_ $\mathrm{id}=3166709$ (accessed on 1 June 2020).

Momtaz, Paul P. 2019a. Token Sales and Initial Coin Offerings: Introduction. The Journal of Alternative Investments 21: 7-12. [CrossRef]

Momtaz, Paul P. 2019b. The Pricing and Performance of Cryptocurrency. The European Journal of Finance. [CrossRef]

Momtaz, Paul P. 2019c. CEO Emotions and Underpricing in Initial Coin Offerings. Available online: https: //papers.ssrn.com/abstract_id=3305765 (accessed on 1 June 2020).

Momtaz, Paul P. 2020a. Initial Coin Offerings, Asymmetric Information, and Loyal CEOs. Small Business Economics. [CrossRef]

Momtaz, Paul P. 2020b. Entrepreneurial Finance and Moral Hazard: Evidence from Token Offerings. Journal of Business Venturing. [CrossRef]

Monks, Robert A. G., and Nell Minow. 1995. Corporate Governance. Cambridge: Basil Blackwell.

Nabilou, Hossein, and André Prum. 2019. Ignorance, Debt and Cryptocurrencies: The Old and the New in the Law and Economics of Concurrent Currencies. Journal of Financial Regulation 5: 29-63. [CrossRef] 
Nakamoto, Satoshi. 2008. Bitcoin: A Peer-To-Peer Electronic Cash System. Available online: https://bitcoin.org/ bitcoin.pdf (accessed on 1 June 2020).

Nowiński, Witold, and Miklós Kozma. 2017. How can Blockchain Technology Disrupt the Existing Business Models? Entrepreneurial Business and Economics Review 5: 173-88. [CrossRef]

Ofir, Moran, and Ido Sadeh. 2019. ICO vs IPO: Empirical Findings, Market Frictions and the Appropriate Regulatory Framework. International Journal of Organizational Leadership 7: 120-28.

Paech, Philpp. 2017. The Governance of Blockchain Financial Networks. Modern Law Review 80: 1073-110. [CrossRef]

Papadopoulos, Georgios. 2015. Blockchain and Digital Payments: An Institutionalist Analysis of Cryptocurrencies. In Handbook of Digital Currency. Edited by David Lee Kuo Chuen. London: Academic Press, pp. 153-72.

Philippon, Thomas. 2016. The FinTech Opportunity. NBER Working Paper, No. 22476. Available online: https://www.nber.org/papers/w22476 (accessed on 1 June 2020).

Piazza, Fiammetta S. 2017. Bitcoin and the Blockchain as Possible Corporate Governance Tools: Strengths and Weaknesses. Penn State Journal of Law \& International Affairs 5: 262-301.

Pilkington, Marc. 2018. The Emerging ICO Landscape-Some Financial and Regulatory Standpoints. Available online: https://ssrn.com/abstract=3120307 (accessed on 1 June 2020).

Primm, Harold. 2016. Regulating the Blockchain Revolution: A Financial Industry Transformation. Review of Banking E Financial Law 36: 75-91.

Proskurovska, Anetta, and Sabine Dörry. 2018. Is a Blockchain-Based Conveyance System the Next Step in the Financialisation of Housing? The Case of Sweden. Available online: https://papers.ssrn.com/bstract_id=3267138 (accessed on 1 June 2020).

Rabah, Kefa V. O. 2017. Overview of Blockchain as the Engine of the 4th Industrial Revolution. Mara Research Journal of Business $\mathcal{E}$ Management 1: 125-35.

Rhue, Lauren. 2018. Trust Is All You Need: An Empirical Exploration of Initial Coin Offerings (ICOs) and ICO Reputation Scores. Available online: https://papers.ssrn.com/abstract_id=3179723 (accessed on 1 June 2020).

Robinson, Randolph II. 2017. The New Digital Wild West: Regulating the Explosion of Initial Coin Offerings. Available online: https://papers.ssrn.com/abstract_id=3087541 (accessed on 1 June 2020).

Robinson, Randolph II. 2018. The New Digital Wild West: Regulating the Explosion of Initial Coin Offerings. Tennessee Law Review 85: 897-960. [CrossRef]

Rohr, Jonathan, and Aaron Wright. 2017. Blockchain-Based Token Sales, Initial Coin Offerings, and the Democratization of Public Capital Markets. Available online: https://papers.ssrn.com/abstract_id=3048104 (accessed on 1 June 2020).

Ron, Dorit, and Adi Shamir. 2013. Quantitative Analysis of the Full Bitcoin Transaction Graph. Berlin and Heidelberg: Springer, pp. 6-24.

Rossow, Andew. 2018. Appraising the Luxury Goods Market with Blockchain Technology. Jersey City: Forbes.

Schindler, John. 2017. FinTech and Financial Innovation: Drivers and Depth; Finance and Economics Discussion Series 2017-081; Washington: Board of Governors of the Federal Reserve System. [CrossRef]

Schroeder, Jeanne L. 2015. Bitcoin and the Uniform Commercial Code. University of Miami Business Law Review 24: 1-80. [CrossRef]

Scott, Brett, John Loonam, and Vikas Kumar. 2017. Exploring the Rise of Blockchain Technology: Towards Distributed Collaborative Organizations. Strategic Change 26: 423-28. [CrossRef]

Shermin, Voshmgir. 2017. Disrupting Governance with Blockchains and Smart contracts. Strategic Change 26: 499-509. [CrossRef]

Sims, Alexandra, Kanchana Kariyawasam, and David Mayes. 2018. Regulating Cryptocurrencies in New Zealand. Wellington: The New Zealand Law Foundation.

Sims, Alexandra. 2019. Blockchain and Decentralised Autonomous Organsiations (DAOs): The Evolution of Companies? New Zealand Universities Law Review 28: 423-458.

Sisli-Ciamarra, Elif. 2012. Monitoring by Affiliated Bankers on Board of Directors: Evidence from Corporate Financing Outcomes. Financial Management 41: 665-702. [CrossRef]

Sockin, Michael, and Wei Xiong. 2020. A Model of Cryptocurrencies. Available online: https://papers.ssrn.com/sol3/ papers.cfm?abstract_id=3550965 (accessed on 1 June 2020). 
Suzuki, Shigeya, and Jun Murai. 2017. Blockchain as an Audit-Able Communication Channel. In Proceedings of the 2017 IEEE 41st Annual Computer Software and Applications Conference (COMPSAC), Turin, Italy, July 4-8; pp. 516-22.

Szabo, Nick. 1994. Smart Contracts. Available online: https://www.fon.hum.uva.nl/rob/Courses/ InformationInSpeech/CDROM/Literature/LOTwinterschool2006/szabo.best.vwh.net/smart.contracts.html (accessed on 1 June 2020).

Tama, Bayu Aadhi, Bruno Joachim Kweka, Youngho Park, and Kyung- Hyune Rhee. 2017. A Critical Review of Blockchain and its Current Applications. In Proceedings of the 2017 International Conference on Electrical Engineering and Computer Science (ICECOS), Palembang, August 22-23; pp. 109-13.

Tanaka, Kenji, Kosuke Nagakubo, and Rikiya Abe. 2017. Blockchain-Based Electricity Rrading with Digitalgrid Router. In Proceedings of the 2017 IEEE International Conference on Consumer Electronics, Taipei, Taiwan, June 12-14; pp. 201-2.

Tapscott, Don, and Alex Tapscott. 2017. How Blockchain will Change Organizations. MIT Sloan Management Review 58: 10-13.

Tasca, Paolo. 2015. Digital Currencies: Principles, Trends, Opportunities, and Risks. Available online: https: //ssrn.com/abstract=2657598 (accessed on 1 June 2020).

Trimborn, Simon, Mingyang Li, and Wolfgang K. Härdle. 2018. Investing with Cryptocurrencies-a Liquidity Constrained Investment Approach. Available online: https://papers.ssrn.com/abstract_id=2999782 (accessed on 1 June 2020).

Tsukerman, Misha. 2015. The Block is Hot: A Survey of the State of Bitcoin Regulation and Suggestions for the Future. Berkeley Technology Law Journal 30: 1127.

Vranken, Harald P.E. 2017. Sustainability of Bitcoin and Blockchains. Current Opinion in Environmental Sustainability 38: 1-9. [CrossRef]

Wang, Huaiqing, Kun Chen, and Dongming Xu. 2016. A Maturity Model for Blockchain Adoption. Financial Innovation 2: 12. [CrossRef]

Wang, Sha, and Jean-Philippe Vergne. 2017. Buzz Factor or Innovation Potential: What Explains Cryptocurrencies' Returns? PLOS ONE 12: e0169556. [CrossRef]

White, Gareth R. T. 2017. Future Applications of Blockchain in Business and Management: A Delphi Study. Strategic Change 26: 439-51. [CrossRef]

Williamson, Oliver E. 1996. Economic Organization: The Case for Candor. The Academy of Management Review 21: 48-57. [CrossRef]

Wright, Aaron, and Primavera De Filippi. 2015. Decentralized Blockchain Technology and the Rise of Lex Cryptographia. Available online: https://papers.ssrn.com/abstract_id=2580664 (accessed on 1 June 2020).

Wu, Tong, and Xiubo Liang. 2017. Exploration and Practice of Inter-Bank Application Based on Blockchain. In Proceedings of the ICCSE 2017 12th International Conference on Computer Science and Education, Houston, TX, USA, August 22-25; pp. 219-24.

Yamada, Yuki, Tatsuo Nakajima, and Mizuki Sakamoto. 2016. Blockchain-LI: A Study on Implementing Activity-Based Micro-Pricing Using Cryptocurrency Technologies. In Proceedings of the 14th International Conference on Advances in Mobile Computing and Multimedia, Singapore, November 28-30; pp. $203-7$. [CrossRef]

Yeoh, Peter. 2017. Regulatory Issues in Blockchain Technology. Journal of Financial Regulation and Compliance 25: 196-208. [CrossRef]

Yermack, David. 2017. Corporate Governance and Blockchains. Review of Finance 21: 7-31. [CrossRef]

Ying, Wenchi, Suling Jia, and Wenyu Du. 2018. Digital Enablement of Blockchain: Evidence from HNA group. International Journal of Information Management 39: 1-4. [CrossRef]

Yli-Huumo, Jesse, Deokyoon Ko, Sujin Choi, Sooyong Park, and Kari Smolander. 2016. Where is Current Research on Blockchain Technology?-A Systematic Review. PLoS ONE 11: e0163477. [CrossRef]

Yoo, Minjae, and Yoojae Won. 2018. Study on Smart Automated Sales System with Blockchain-Based Data Storage and Management. In Advances in Computer Science and Ubiquitous Computing. Singapore: Springer, vol. 474, pp. 734-40.

Zalan, Tatiana. 2018. Born Global on Blockchain. Review of International Business and Strategy 28: 19-34. [CrossRef] Zavolokina, Liudmila, Mateusz Dolata, and Gerhard Schwabe. 2016. The FinTech Phenomenon: Antecedents of Financial Innovation Perceived by the Popular Press. Financial Innovation 2: 1-16. [CrossRef] 
Zetzsche, Dirk. A., Ross P. Buckley, Douglas W. Arner, and Janos Nathan Barberis. 2017. From FinTech to TechFin: The Regulatory Challenges of Data-Driven Finance. Available online: https://ssrn.com/abstract=2959925 (accessed on 1 June 2020).

Zetzsche, Dirk. A., Ross P. Buckley, Douglas W. Arner, and L. Föhr. 2018. The ICO Gold Rush: It's a Scam, It's a Bubble, It's a Super Challenge for Regulators. Harvard International Law Journal 60: 267-315. [CrossRef]

Zheng, Zibin, Shaoan Xie, Hong-Ning Dai, Xianping Chen, and Huaimin Wang. 2018. Blockchain Challenges and Opportunities: A Survey. International Journl Web and Grid Services 14: 352-75. [CrossRef]

Zhu, Huasheng, and Zach Zhizhong Zhou. 2016. Analysis and Outlook of Applications of Blockchain Technology to Equity Crowdfunding in China. Financial Innovation 2: 29. [CrossRef]

(C) 2020 by the authors. Licensee MDPI, Basel, Switzerland. This article is an open access article distributed under the terms and conditions of the Creative Commons Attribution (CC BY) license (http://creativecommons.org/licenses/by/4.0/). 